\title{
EXPERIMENTAL TEST SIMULATING A COLUMN LOSS IN A COMPOSITE FRAME
}

\author{
Jean-François Demonceau* and Jean-Pierre Jaspart \\ University of Liège, Argenco Department, Chemin de Chevreuils, 1 B52/3 4000 Liège, Belgium \\ *(Corresponding author: E-mail: jfdemonceau@ulg.ac.be)
}

Received: 31 January 2010; Revised: 1 February 2010; Accepted: 4 February 2010

\begin{abstract}
Recent events such as natural catastrophes or terrorism attacks have highlighted the necessity to ensure the structural integrity of buildings under exceptional events. According to Eurocodes and some different other national design codes, the structural integrity of civil engineering structures should be ensured through appropriate measures. Design requirements are proposed in some codes but are nowadays seen generally as not satisfactory. In particular, it is not demonstrated that, even if these requirements are respected, the risk of a progressive collapse of the structure subjected to an exceptional event will really be mitigated.

A European RFCS project entitled "Robust structures by joint ductility" has been set up in 2004, for three years, with the aim to provide requirements and practical guidelines allowing to ensure the structural integrity of steel and composite structures under exceptional events through an appropriate robustness. In particular, one substructure test simulating the loss of a column in a composite building was performed at Liège University. The present paper describes in details this substructure test. In particular, the development of membrane forces is illustrated and their effects on the behaviour of the beam-to-column joints are discussed.
\end{abstract}

Keywords: Column loss, experimental test, composite structure, membrane forces, robustness

\section{INTRODUCTION}

Recent events such as natural catastrophes (tsunami, hurricane, ...) or terrorism attacks have highlighted the necessity to ensure the structural integrity of buildings under exceptional events, with the objective to save the life of the occupants and of the safety services (fireman, ambulance man, ...) but also to avoid collateral damages to the adjacent buildings.

The partial collapse of the Ronan Point Tower in 1968 in UK is considered as the starting point of the researches on the structural integrity of buildings; but more recent catastrophes in the last decade such as the terrorist attack of the World Trade Center towers in 2001 or the tsunami associated to the Sumatra earthquake in 2004 have further increased the interest of the engineering community and of the population in this topic.

According to Eurocodes and some different other national design codes, the structural integrity of civil engineering structures should be ensured through appropriate measures. Design requirements are proposed in some codes but are generally not satisfactory. In particular, it is not demonstrated that, even if these requirements are respected, a structure subjected to an exceptional event will really behave properly.

In this context, a European RFCS project called "Robust structures by joint ductility" (Kuhlmann et al [1]) has been set up in 2004, for three years, with the aim to provide requirements and practical guidelines allowing to ensure the structural integrity of steel and composite structures under exceptional events through an appropriate robustness. 
The investigations performed at Liège University, as part of this European project, were mainly dedicated to the exceptional event "loss of a column in a steel or steel-concrete 2D composite building frame"; the main objective was to develop a simplified analytical procedure to predict the frame response further to a column loss.

To achieve this goal, a global strategy has been developed at Liège University; this one is described briefly here below.

When a structure is losing a column, for instance further to an impact, it may be divided in two main parts, as illustrated in Figure 1:

- the directly affected part which is the one directly affected by the loss of the column, i.e. the beams, the columns and the beam-to-column joints which are just above the impacted column and;

- the indirectly affected part which, on one side, is affected by forces transferred from the directly affected part and which, on the other side, influences the response of the directly affected part.

At the top of the column, before it is fully removed (see Figure 1), the following internal forces are identified in the vertical direction:

- $\quad$ the shear forces $\mathrm{V}_{1}$ and $\mathrm{V}_{2}$ at the beam extremities;

- the axial force $\mathrm{N}_{\mathrm{up}}$ in the column just above the impacted one and;

- the axial force $\mathrm{N}_{\mathrm{lo}}$ in the impacted column.

The objective of the studies performed at Liège University was to predict the evolution of $\mathrm{N}_{\mathrm{lo}}$ versus the vertical displacement of point " $\mathrm{A}$ " $\Delta_{\mathrm{A}}$, with due account of the possible membrane forces developing in the structure; from this knowledge, the ductility required from the structural members and joints and the resistance of the indirectly affected part overloaded by forces transferred by the directly affected part may be derived in a second step.

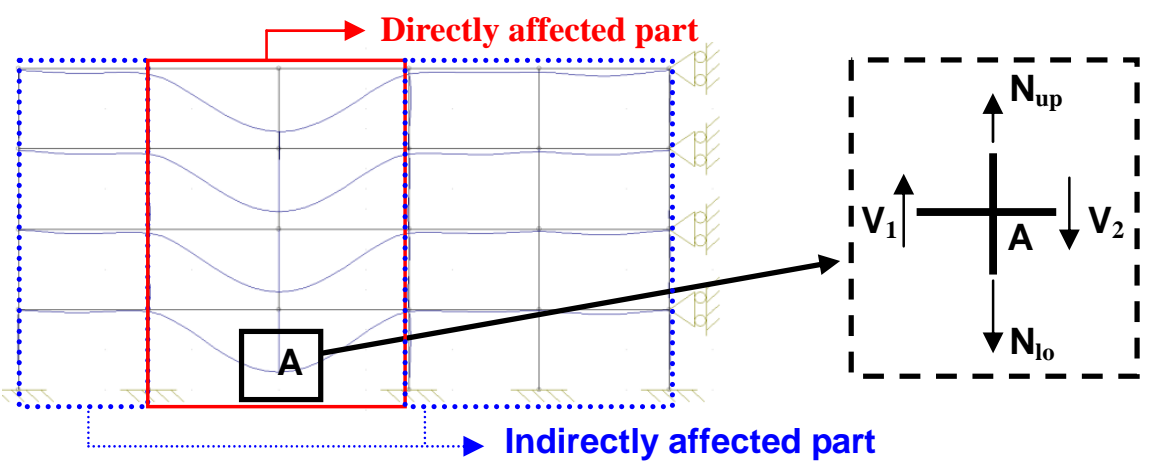

Figure 1. Representation of a Frame Losing a Column and Main Definitions

In Figure 2, the curve illustrating the evolution of the normal load $N_{l o}$ in the loss column (see Figure 1) versus the vertical displacement $\Delta_{a}$ is illustrated:

- From point (1) to (2) (Phase 1), the design loads are progressively applied to the non-damaged structure ("conventional" loading); so, $N_{l o}$ decreases (negative sign for compression) while $\Delta_{A}$ can be assumed to be equal to 0 during this phase (in reality, there is a small vertical displacement at point A associated to the shortening of the columns below point " $\mathrm{A}$ "). It is assumed that no yielding during this phase, i.e. the frame remains fully elastic.

- From point (2) to (5), the column is progressively removed. From point (2), $N_{\text {lo }}$ increases until it reaches a value equal to 0 at point (5) where the column can be considered as fully destroyed. 
So, in this zone, the absolute value of $N_{l o}$ is progressively decreasing while the value of $\Delta_{A}$ is increasing. This part of the graph is divided in two phases as shown in Figure 2:

- From point (2) to (4) (Phase 2): during this phase, a plastic mechanism progressively forms in the directly affected part. Point (3) corresponds to the development of a first plastic hinge.

- Point (4) to (5) (Phase 3): here, large displacements are observed and second order geometrical effects play an important role. In particular, significant membrane forces are developing in the bottom beams of the directly affected part.

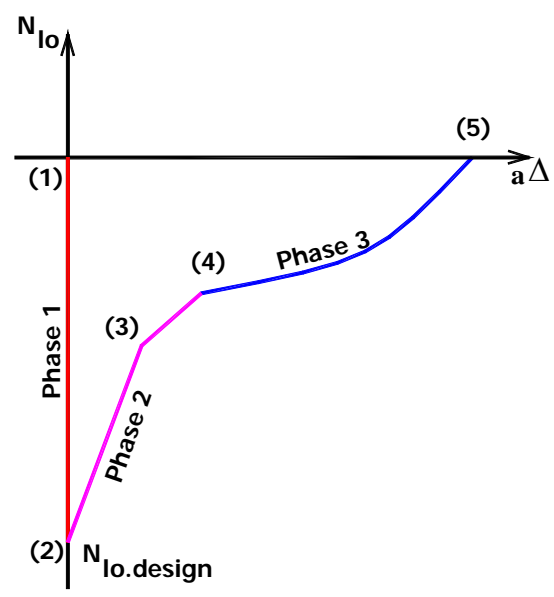

Figure 2. Evolution of $N_{l o}$ Versus the Vertical Displacement at the Top of the Impacted Column

It is only possible to pass from point (1) to (5) if:

- the forces which are transferred from the directly affected part to the indirectly affected part do not induce, in the latter, the failure of structural elements (for instance, buckling of the columns or formation of a plastic mechanism in the indirectly affected part);

- if the different structural members and joints have a sufficient ductility to reach the vertical displacements corresponding to point (5).

Obviously, the complete removal of the column could be reached (i.e. $N_{l o}=0$ ), in some cases, before reaching Phase 3.

To investigate the behaviour of the structure during Phase 3, i.e. when significant membrane forces develop, the following approach has been defined (Demonceau [2]):

- Step 1: an experimental test has been carried out on a substructure with the aim to simulate the loss of a column in a composite building frame.

- Step 2: analytical and numerical FEM tools have been validated through comparisons with the experimental results

- Step 3: parametric studies based on the use of the models validated at step 2 have been carried out; the objective was to identify the parameters influencing the frame response during Phase 3.

- Step 4: a simplified analytical method has been developed with due account of the parameters identified at step 3 and validated through comparisons with the experimental test results of step 1.

For sake of simplicity, all the conducted investigations are based on the assumption that no significant dynamic effects are associated to the exceptional event. So, only the static response of the system is investigated here even if extra developments on dynamic effects have been initiated in the meantime at Liège University. 
The present paper only focused on the experimental test performed at Liège University as part of the "Robustness" project (Kuhlmann et al [1]), i.e. on Step 1. Details about the other steps are available in (Demonceau [2]) which is freely downloadable at http://orbi.ulg.ac.be/handle/2268/2740.

The main objective of the test was to observe the development of membrane forces within a frame and the effect of these actions on the response of semi-rigid and partial-strength composite beam-to-column joints. Indeed these joints are initially designed for bending and shear forces, but have progressively to resist to tensile forces as a result of the development of membrane tying forces in the beams.

To define the substructure to be tested, an "actual" composite building has been first designed according to Eurocode 4 (EN 1994-1-1 [3]), under "conventional” loading conditions (i.e. loads recommended in Eurocode 1 (EN 1991-1-1 [4]) for office buildings); the aim was to obtain realistic structural dimensions and member profiles. The designed building is presented in $\S 2$.

As it was not possible to test a full 2-D actual composite frame within the "Robustness" project, a substructure described in $\S 3$ has been then extracted from the above EC4 designed building; the extracted substructure has been defined so as to respect the dimensions of the testing slab but also to exhibit a similar behaviour as the one which would have been observed in the actual frame.

Finally, the realisation of the test as well as the test results are described in $\S 4$.

\section{DESIGN OF AN “ACTUAL” COMPOSITE BUILDING}

As said in the previous section, an "actual" composite building subjected to "conventional" loading is first designed according to Eurocode 4 (EN 1994-1-1 [3]). The general layout of the building and one of its main frames are presented in Figure 3.
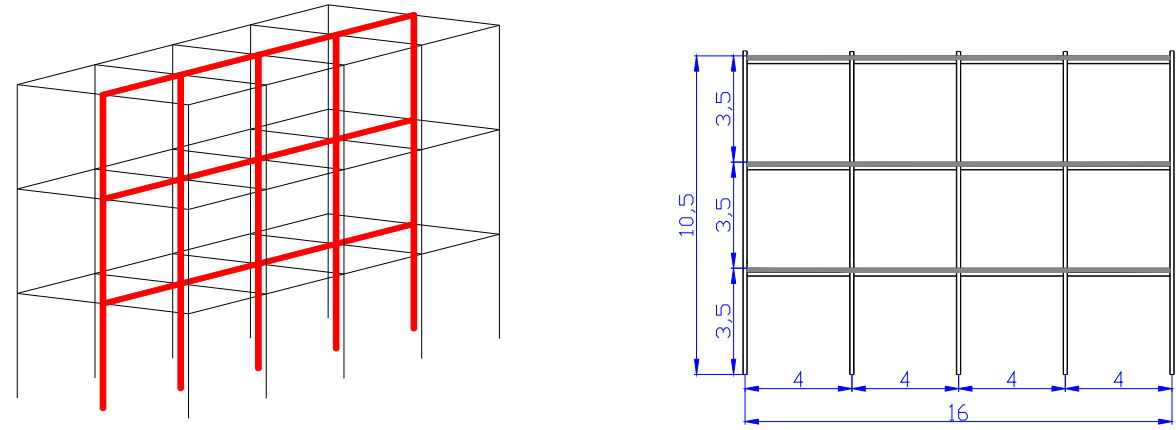

Figure 3. 3D View of the Designed Building and Details of One of the Main Frames

The building is composed of three main frames, $3 \mathrm{~m}$ spaced. The main frames are four bays - three storeys ones with a total width of $16 \mathrm{~m}$ (bay span $=4 \mathrm{~m}$ ) and a total height of 10,5 $\mathrm{m}$ (storey height $=3,5 \mathrm{~m}$ ). The loads which have been considered for the design of the structural elements are the following: the self-weight, a permanent load of $2 \mathrm{kN} / \mathrm{m}^{2}$ and an imposed load of $3 \mathrm{kN} / \mathrm{m}^{2}$ (load recommended for office building in Eurocode 1 (EN 1991-1-1 [4]).

The main frames are assumed to be braced/non-sway and the column bases to be perfect hinges. In a first approach, the external joints are assumed to be fully pinned and the internal ones to be fully rigid; the validity of these assumptions will be checked later on in $\S 2.2$ dealing with the design of joints. The static scheme of the main frame is shown in Figure 4. 


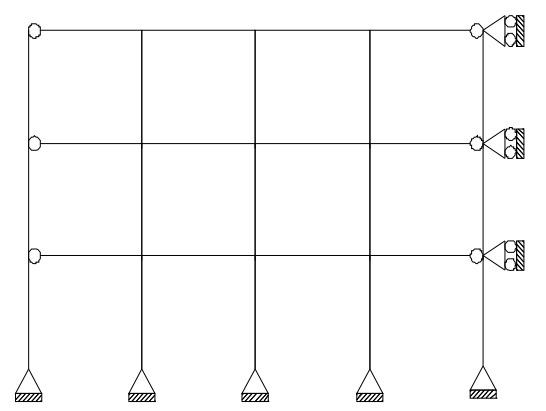

Figure 4. Static Scheme for the Main Frame

\subsection{Design of the Structural Members}

The design of the selected main frame is detailed in (Demonceau [2]); the following structural members result from the design:

- The slab is a reinforced concrete one with a thickness of $120 \mathrm{~mm}$ and made of a C25/30 concrete $\left(f_{c k}=25 \mathrm{~N} / \mathrm{mm}^{2}\right)$. The reinforcement is composed of two meshes: one at the top with $200 \mathrm{~mm}$ spaced $10 \mathrm{~mm}$ rebars and one at the bottom with $150 \mathrm{~mm}$ spaced $10 \mathrm{~mm}$ rebars. The steel grade for these rebars is S500C (high ductility rebars with $f_{s k}=450 \mathrm{~N} / \mathrm{mm}^{2}$ ) and the cover is equal to 25 $\mathrm{mm}$. The cross-section of the slab is presented in Figure 5.

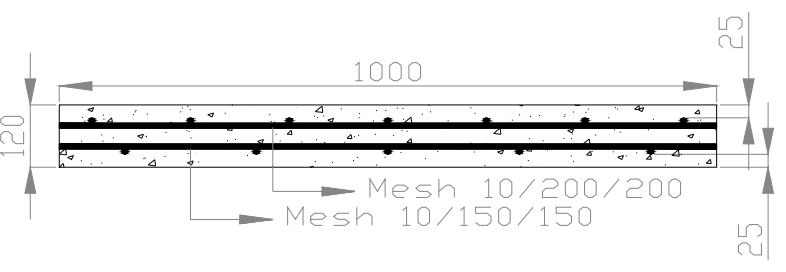

Figure 5. Slab Cross Section

- The beams are composite ones (upper flange of the profile connected to the concrete slab). The steel part of the beam is an IPE140 profile with a S355 steel grade (fyk $=355 \mathrm{~N} / \mathrm{mm}^{2}$ ); the beam composite cross-section is shown in Figure 6. A full shear connection is achieved between the profile and the concrete slab; the number of studs (Nelson studs with a diameter equal to $16 \mathrm{~mm}$ and a height of $75 \mathrm{~mm}-\mathrm{fu}=450 \mathrm{~N} / \mathrm{mm}^{2}$ ) required to ensure this full connection is indicated in Figure 7.

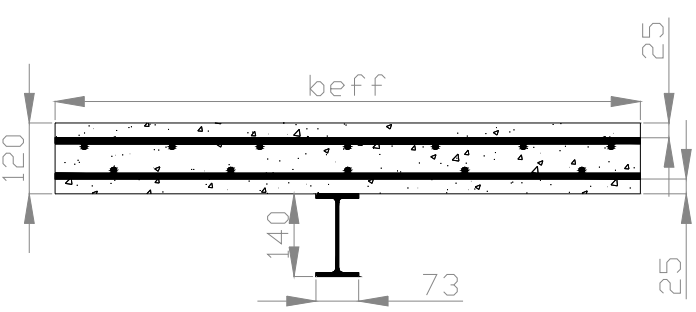

Figure 6. Composite Beam Cross-Section

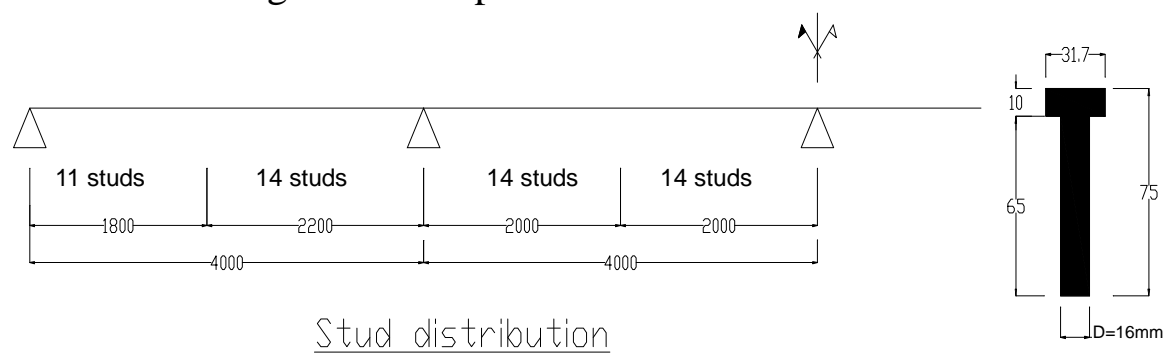

Figure 7. Distribution of the Studs along the Composite Beam Length 
- $\quad$ The columns are steel ones. The profile is an HEA160 with a S355 steel grade.

\subsection{Design of the Structural Joints Subjected to Hogging Bending Moments}

\subsubsection{Design of the external steel joints}

For these joints, it is assumed that the concrete slab is not extended beyond the front face of the external columns (Figure 8); so, they will be considered as steel ones.
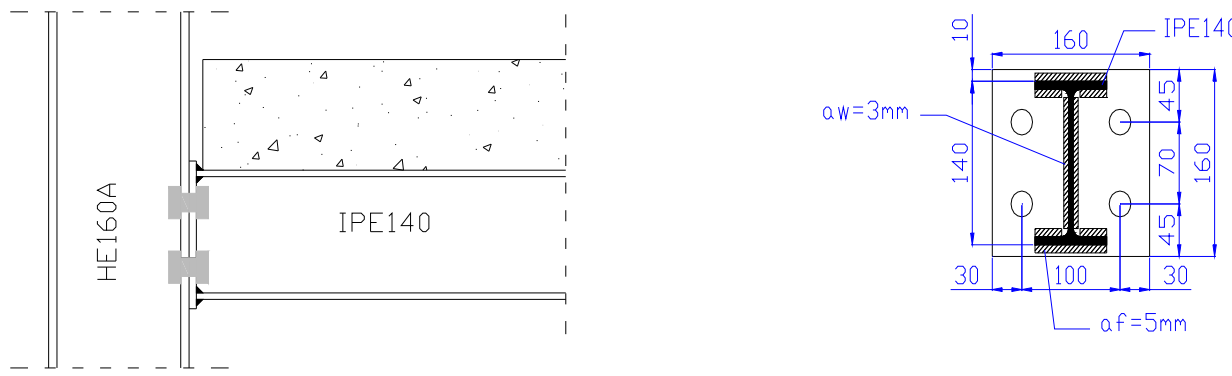

Figure 8. External Steel Joint Configuration and Geometrical Properties of the End-Plate

The joint properties have been chosen so as to ensure a ductile behaviour of the joint at failure and that, with due account of possible overstrength effects. To achieve this goal, only ductile components are activated at failure. The selected connection is a flush-end plate bolted one. Figure 8 gives the geometrical properties of the end-plate.

The bolts are M20 8.8 ones. The end-plate thickness is equal to $8 \mathrm{~mm}$. The steel grade for all the steel components of the joint is S355; a possible overstrength of $35 \%$ (value proposed in Eurocode 8 for seismic design (EN 1998-1-1 [5])) may be expected.

As far as loading is concerned, different situations have been considered in the joint design so as to be sure that, even if overstrength occurs in some components, the joint still fail through a ductile mode. The resulting joint mechanical properties for these different situations are summarised in Table 1; they have been computed by means of the software CoP (www.connectionprogram.com) which is in full agreement with the Eurocode recommendations.

The initial stiffness of the external joints is equal to $970 \mathrm{kNm} / \mathrm{rad}$; the latter is higher than $0,5 E I_{b} / L$ $=890 \mathrm{kNm} / \mathrm{rad}\left(E I_{b}\right.$ is conservatively taken as the uncracked flexural stiffness of the composite cross-section of the beam and $L$ is the span of the beam), which is the upper limit under which a joint can be assumed as pinned. So, strictly speaking, the assumption of pinned external joints in the actual composite building design is not validated. Accordingly, a computation of the internal frame modelled with the predicted properties of the joints has been performed and the internal forces have been compared to the resistance of the joint; the obtained results are presented later on in $\S 2.3$. 
Table 1. Properties of the External Steel Joints with Account of Possible Overstrength Effects

\begin{tabular}{|c|c|c|c|c|c|c|}
\hline & Overstrength & $\begin{array}{c}M_{R d} \\
{[\mathrm{kNm}]}\end{array}$ & $\begin{array}{c}M_{e} \\
{[\mathrm{kNm}]}\end{array}$ & Failure mode & $\begin{array}{c}V_{R d} \\
{[\mathrm{kN}]}\end{array}$ & $\begin{array}{c}S_{j, \text { ini }} \\
{[\mathrm{kNm} / \mathrm{rad}]}\end{array}$ \\
\hline $\begin{array}{l}\text { Initial } \\
\text { situation }\end{array}$ & $\begin{array}{c}\text { No } \\
\text { overstrength }\end{array}$ & 15,1 & 10,1 & $\begin{array}{l}\text { End-plate in } \\
\text { bending }\end{array}$ & 134,4 & 970 \\
\hline $2^{\circ}$ situation & End-plate & 16,6 & 11,1 & $\begin{array}{l}\text { Column flange in } \\
\text { bending }\end{array}$ & 134,4 & 970 \\
\hline $3^{\circ}$ situation & $\begin{array}{l}\text { End-plate }+ \\
\text { column }\end{array}$ & 19,9 & 13,3 & $\begin{array}{l}\text { Beam flange in } \\
\text { compression }\end{array}$ & 134,4 & 970 \\
\hline $4^{\circ}$ situation & $\begin{array}{c}\text { End-plate }+ \\
\text { column }+ \\
\text { beam }\end{array}$ & 20,5 & 13,7 & $\begin{array}{l}\text { End-plate in } \\
\text { bending }\end{array}$ & 134,4 & 970 \\
\hline
\end{tabular}

with $M_{R d}$, the resistant moment of design, $M_{e}$, the elastic resistant moment of design (= $2 / 3 M_{R d}$ ), $V_{R d}$, the shear resistance and $S_{j, i n i}$, the initial stiffness of the joint.

\subsubsection{Design of the internal composite joints}

The steel components are the same than those characterising the external steel joints presented in the previous section. A sketch of the internal composite joints may be seen in Figure 9.

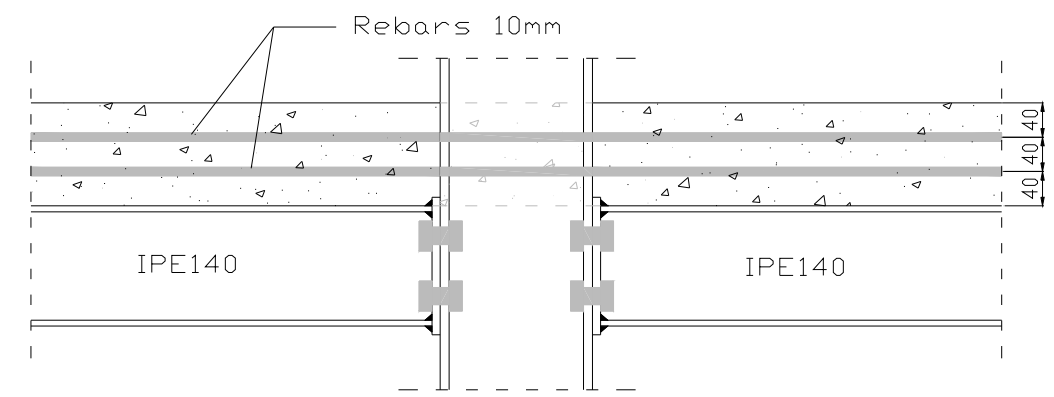

Figure 9. Internal Composite Joint Configuration

The mechanical properties of this joint configuration have been computed according to Eurocode recommendations. The mechanical properties of the internal composite joints for different overstrength situations are summarised in Table 2 (assuming that the internal joint is symmetrically loaded).

The initial stiffness of the internal joints is equal to $7541 \mathrm{kNm} / \mathrm{rad}$; the latter is lower than $8 E I_{b} / L=$ $14240 \mathrm{kNm} / \mathrm{rad}$, which is the lower limit above which a joint may be assumed as rigid. So, the assumption of fully-rigid internal joints when analysing this reference building is not satisfied. As previously, a computation of the internal frame based on the actual properties of the joints has been performed and the internal forces have been compared to the resistance of the joint (see $\S 2.3$ ). 
Table 2. Properties of the Internal Composite Joints with Account of Possible Overstrength Effects

\begin{tabular}{|c|c|c|c|c|c|c|}
\hline & Overstrength & $\begin{array}{c}M_{R d} \\
{[\mathrm{kNm}]}\end{array}$ & $\begin{array}{c}M_{e} \\
{[\mathrm{kNm}]}\end{array}$ & Failure mode & $\begin{array}{c}V_{R d} \\
{[\mathrm{kN}]}\end{array}$ & $\begin{array}{c}S_{j, \text { ini }} \\
\text { [kNm/rad] }\end{array}$ \\
\hline $\begin{array}{l}\text { Initial } \\
\text { situation }\end{array}$ & No overstrength & 39,8 & 26,5 & $\begin{array}{l}\text { Beam flange in } \\
\text { compression }\end{array}$ & 134,4 & 7541 \\
\hline $2^{\circ}$ situation & Beam & 46,8 & 31,2 & $\begin{array}{l}\text { Column web in } \\
\text { compression }\end{array}$ & 134,4 & 7541 \\
\hline $3^{\circ}$ situation & Beam + column & 47 & 31,3 & $\begin{array}{l}\text { Reinforcement in } \\
\text { tension + end-plate } \\
\text { in bending }\end{array}$ & 134,4 & 7541 \\
\hline $4^{\circ}$ situation & $\begin{array}{l}\text { Beam + column } \\
+ \text { end-plate }\end{array}$ & 49,8 & 33,2 & $\begin{array}{c}\text { Beam flange in } \\
\text { compression }\end{array}$ & 134,4 & 7541 \\
\hline
\end{tabular}

\subsubsection{Conclusions}

From the previous results, it can be concluded that all the structural joints within the reference frame are semi-rigid and partially resistant. The failure of the external steel joints is associated to components in tension while that of the internal composite joints is linked to components in compression. It is due to the fact that, in the composite joint configuration, an additional component, the reinforcement in tension, is activated; so, the total resistance of the tension zone is increased.

The failure modes, for the two joint configurations, are ductile, even if overstrength has been seen to be present in some components. Nevertheless, there is a difference in the post-limit behaviour of the two joints as the failure modes are not the same. This difference, illustrated in Figure 10, is explained here below:

- For the composite internal joints with a failure associated to a component in compression: when $M_{R d}$ is reached, the joint cannot sustain this bending moment (no plateau in the behavioural curve) and the bending moment at the joint level decreases rapidly.

- For the steel external joints with a failure associated to a component in tension: when $M_{R d}$ is reached, the joint can sustain this bending moment (sort of plateau in the behavioural curve) while the internal joint rotation increase.

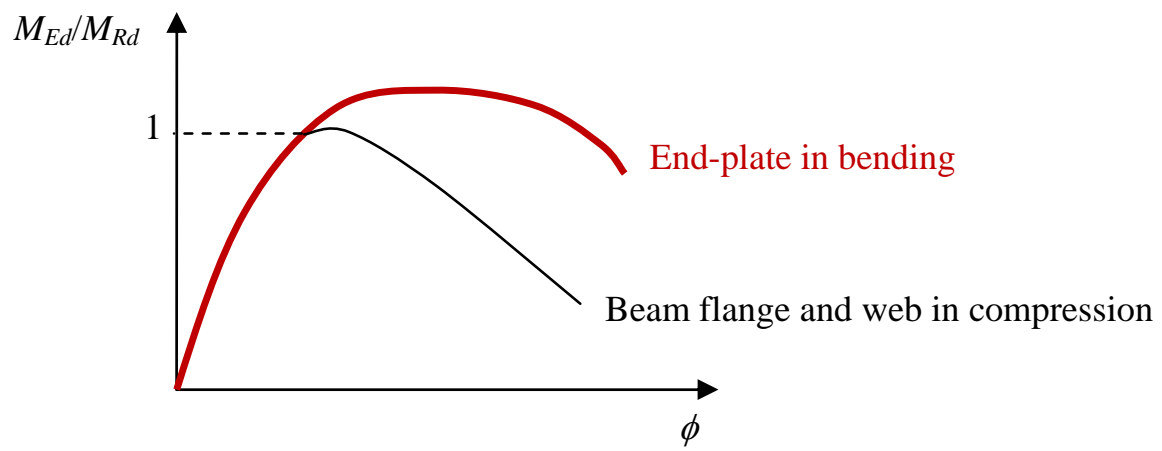

Figure 10. Comparison of Joint Behavioural Curves for Different Types of Failure Modes

In conclusion, both joints are seen to exhibit a significant "rotation capacity" and therefore a significant level of ductility.

When a classical plastic structural analysis is performed, two properties are of importance where plastic hinges form (in members or joints):

- Ductility in rotation and;

- Ability to sustain $M_{R d}$ in the post-limit range. 
In the present case, to ensure a good behaviour of the joint under exceptional loading, the ability to sustain $M_{R d}$ in the post-limit range is not required. Indeed, to have robustness, only ductility is requested. The rotation capacity of the joint must be sufficient so as to allow the hinge to rotate, whatever is the moment transferred through the joint.

\subsection{Ultimate State Verification of the Internal Main Frame with due Account of the Actual Joint Properties}

As the actual joints are semi-rigid, the internal main frame has to be re-analysed taking into account of the predicted properties of the joints. Different load cases are considered; some examples are presented in Figure 11.
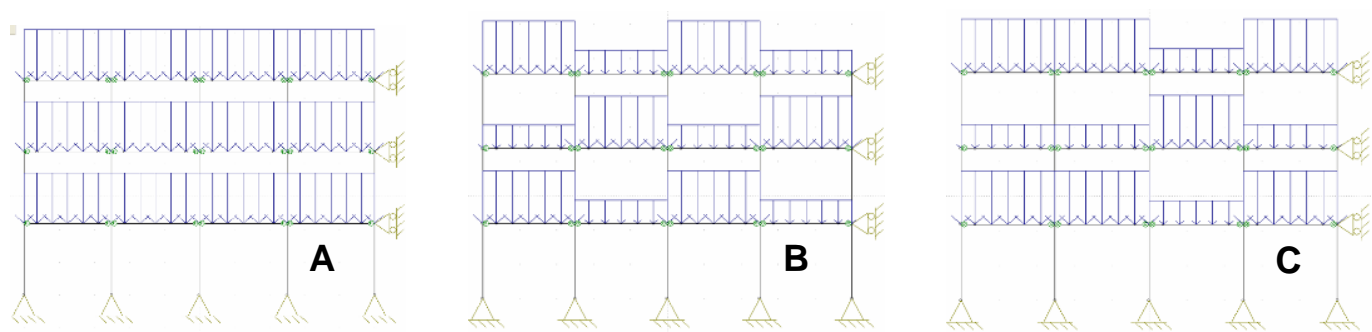

Figure 11. Examples of Considered Load Cases

Through these analyses, it is shown that the designed building respects the ultimate and the serviceability limit states (Demonceau [2]).

\subsection{Conclusions}

In this section, a three storeys - four bays composite frame has been defined; all the structural members (i.e. the composite beams, the steel columns and the composite joints) have been checked in accordance with the Eurocodes. The joints have been designed as partial-strength, with ductile modes of collapse (taking into account possible material overstrength).

In the next section, the substructure tested at Liège University is isolated from the previously defined "actual” building.

\section{SUBSTRUCTURE EXTRACTED FOR TESTING}

As mentioned in $\S 1$, the objective of the substructure test is to investigate the behaviour of a composite structure further to a column loss. According to the project budget and the laboratory facilities, it was not possible to test the full composite frame previously described. So, a substructure has been extracted from the latter; this substructure has been designed so as to conform to the laboratory facilities and to exhibit a behaviour as close as possible to the one of the actual frame. In the present paragraph, the extracted substructure is described.

\subsection{Substructure Layout}

To perform the test, the bottom storey is isolated from the internal frame of the actual building. To accommodate the dimensions of the testing slab, the $16 \mathrm{~m}$ width is reduced to $11 \mathrm{~m}$, as illustrated in Figure 12, through the limitation of the external spans. 
The width of the concrete slab is taken equal to $500 \mathrm{~mm}$ (see Figure 13). It has been fixed so as to be sure that, during the loading, the distribution of the stresses within the concrete is as close as possible to a uniform one; $500 \mathrm{~mm}$ corresponds to the value of the effective width of the concrete slab in the actual building for the hogging moment zone (according to the recommendations of Eurocode 4 (EN 1994-1-1 [3])).

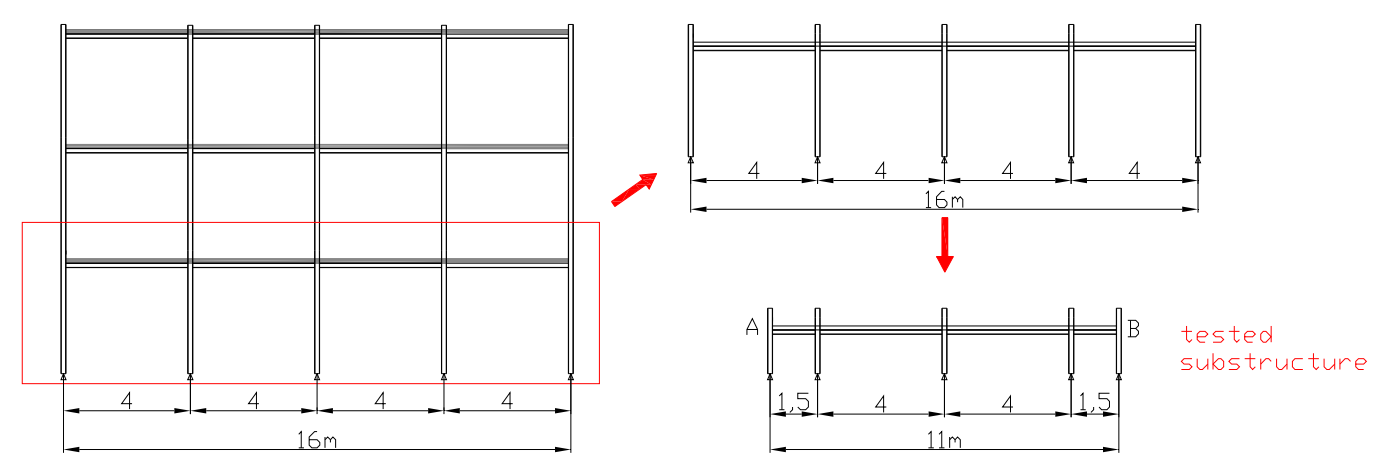

Figure 12. From the Actual Frame to the Tested Substructure

\subsection{Reinforcement and Stud Layouts}

The reinforcement and the studs in the concrete slab have been fixed in collaboration with Stuttgart University. First, it has been agreed to use six $8 \mathrm{~mm}$ rebars for the longitudinal reinforcement (151 $\mathrm{mm}^{2}$ ) instead of four $10 \mathrm{~mm}$ ones $\left(157 \mathrm{~mm}^{2}\right)$, which are the rebars included within the $500 \mathrm{~mm}$ width in the actual frame (see $\S 2$ ). The objective of this modification is to increase the probability to have a distributed small cracks along the slab during the loading instead of big cracks which have to be avoided from the ductility point of view. For the transversal rebars, $10 \mathrm{~mm}$ rebars are used as illustrated in Figure 13.
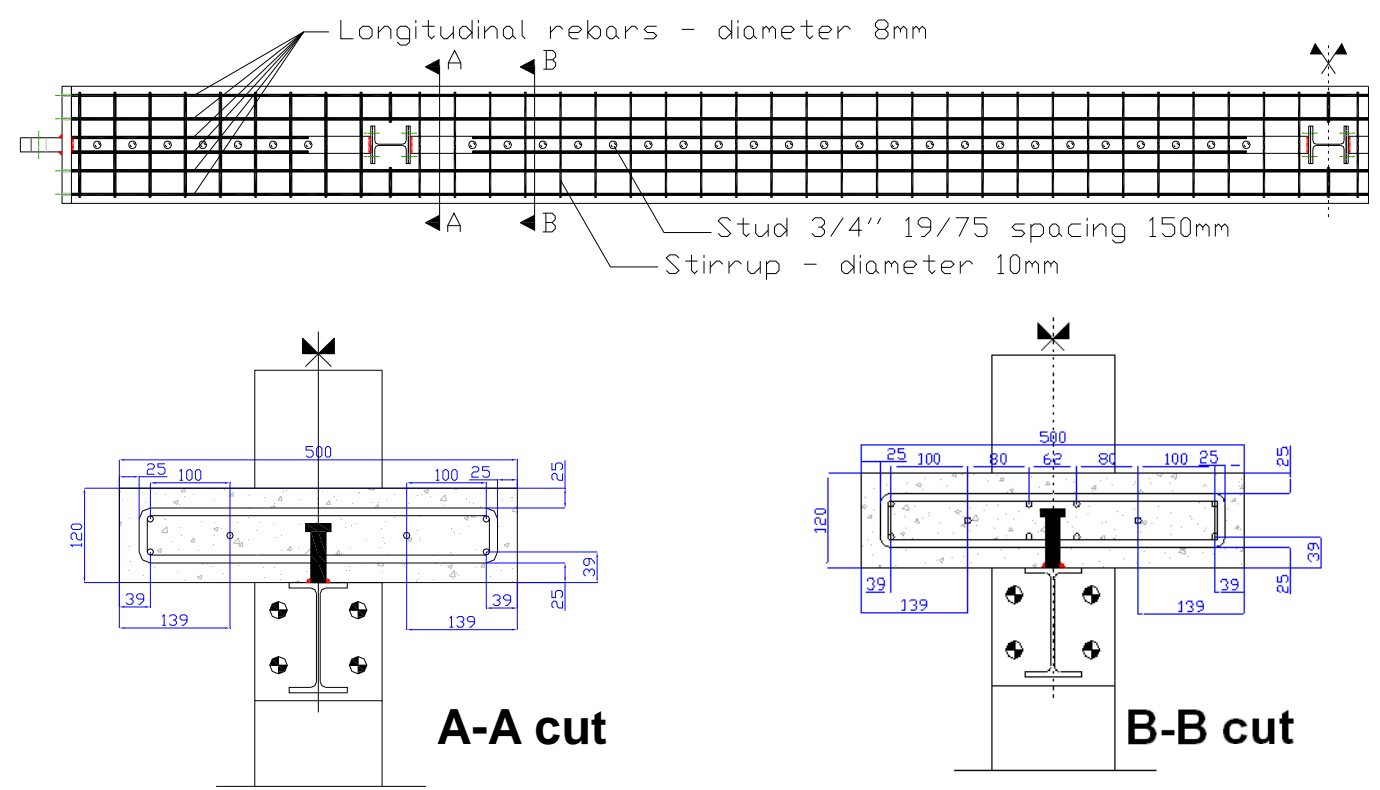

Figure 13. Reinforcement and Stud Layouts

Secondly, the layout of the headed studs and the reinforcement has been chosen in a way that a tension band can develop in the concrete slab, with an especially high ductile behaviour. Therefore 
the distance between the first stud and the face of the column flange is increased compared to standard layout while the amount of reinforcement within this area is kept constant (see Figure 13); this type of layout has already been investigated in a previous project conducted by Kuhlmann/Schäfer (Kuhlmann [6]) and showed good results. Also, it has been decided to use studs with a diameter of $19 \mathrm{~mm}$ instead of $16 \mathrm{~mm}$, what permits to limit the number of studs required to ensure a full connection (23 studs in the internal composite beam instead of 28 - see Figure 7).

\subsection{Joint and Column Base Configurations within the Substructure}

At the column bases, actual hinges are realised (Figure 14); Teflon elements are put between the pin and the column support so as to limit the friction between these two elements during the test.

The composite joint configuration in the substructure is the same than the one in the actual building. However, for the joints between the external beams and the external columns (Beam A and Column A respectively in Figure 16), it has been decided to substitute perfect hinges (as shown in Figure 14) to the actual external joints so as to limit the number of parameters which could influence the response of the internal beams being specifically investigated (Beam B in Figure 16).
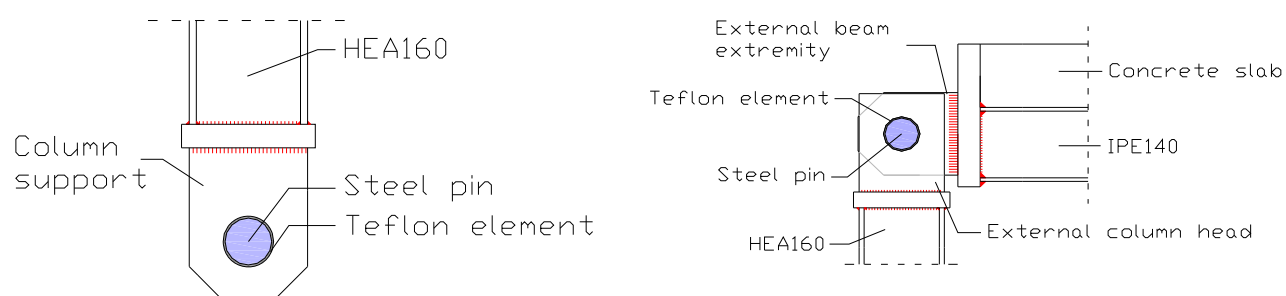

Figure 14. Column Support and Hinge between the External Beam and the External Column

\subsection{Simulation of the Lateral Restraint during the Test}

As previously mentioned, the tested substructure is defined so as to exhibit a behaviour as close as possible to the one of the actual frame. By isolating the substructure from the actual frame, reducing the length of the external spans and realizing actual hinges at the external joints, a key element has been modified: the lateral restraint called " $K$ " brought by the directly affected part (see Figure 1) which influences the development of the membrane forces in the internal beams.

To overcome this problem, "artificial” lateral restraints are activated; they are located each side of the substructure (see point A and B in Figure 12) to induce a "symmetrical" response of the substructure during the test (see Figure 15), what facilitates the application of the loads and the measurements.

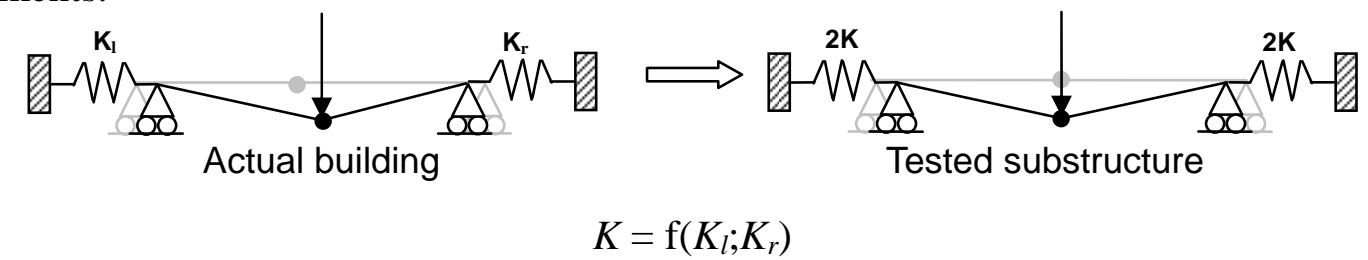

Figure 15. Symmetric Response of the Tested Substructure

These restraints are brought by two horizontal jacks (see Figure 16) which are calibrated so as to exhibit a response close to the actual one, determined numerically through the study of the full "actual" building frame (for the loss of a column at the middle of the bottom storey $-K=1650$ $\mathrm{kN} / \mathrm{m}$ ); the restraint is assumed to be elastic from the beginning to the end of the test (see Figure 17). 


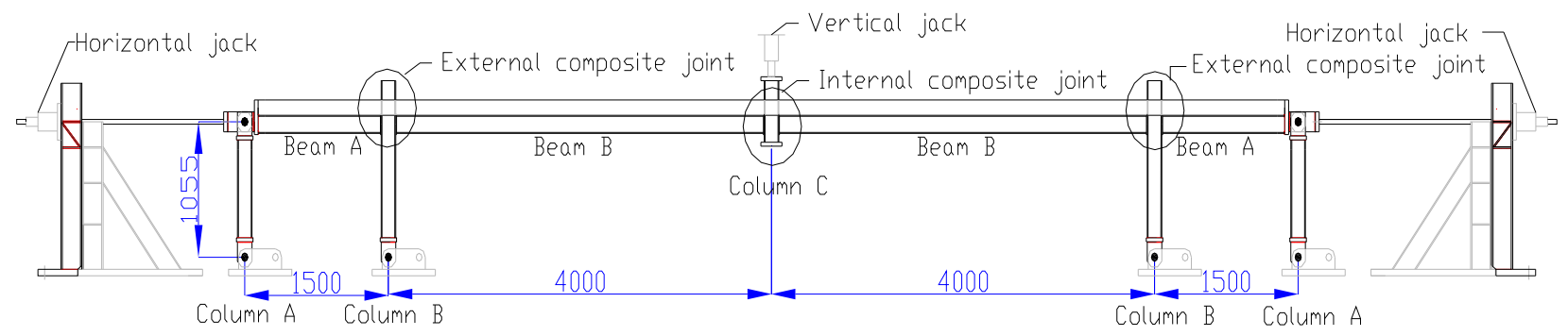

Figure 16. Detailed Illustration of the Substructure Test

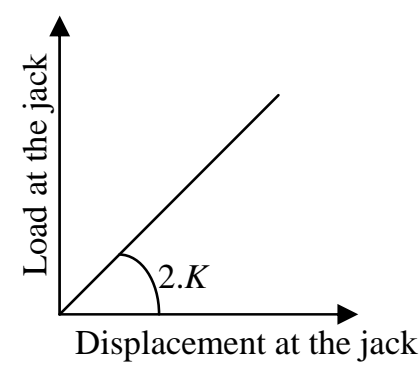

Figure 17. Calibration of the Horizontal External Jacks

\subsection{Conclusions}

This section describes the substructure extracted from the actual building frame to be tested in laboratory.

Some modifications have been realised to pass from the actual frame to the tested substructure with the aim to respect the laboratory facilities and to facilitate the interpretation of the results; all these modifications have been described and justified.

In the next section, the substructure test is described and the obtained results are presented.

\section{SUBSTRUCTURE TEST}

The test in itself and the obtained results are described in the present section which is divided as follows:

- tests aiming at characterising the properties of the constitutive materials are first presented in $\S$ 4.1 ;

- $\quad$ the actual geometrical properties of the tested specimen are given in $\S 4.2$;

- $\quad \S 4.3$ describes the loading sequence applied during the test;

- $\quad$ the test setup and measurements are presented in $\S 4.4$;

- $\quad$ finally, the test results are discussed in $§ 4.5$.

\subsection{Characterization of the Constitutive Materials}

\subsubsection{Steels}

The mechanical properties of the steel materials have been determined through coupon tests; they are presented from Table 3 to Table 5 (Demonceau [2]). In the "Robustness" project mentioned before (Kuhlmann [1]), different tests were also performed at Stuttgart University and Trento University on joints in isolation and on joint components respectively, using steel elements coming from the same production and the same rolling than the ones used for the substructure; accordingly, 
the values reported hereafter are average values of coupon test results obtained in the different laboratories.

Table 3. Mechanical Properties of the Steels for Profiles

\begin{tabular}{|c|ccc|cccc|}
\hline \multirow{2}{*}{ IPE140 } & $\begin{array}{c}f_{y, \text { web }} \\
{\left[\mathrm{N} / \mathrm{mm}^{2}\right]}\end{array}$ & $\begin{array}{c}f_{\text {y,flange }} \\
{\left[\mathrm{N} / \mathrm{mm}^{2}\right]}\end{array}$ & $\begin{array}{c}f_{\text {y,average }} \\
{\left[\mathrm{N} / \mathrm{mm}^{2}\right]}\end{array}$ & $\begin{array}{c}f_{u \text { web }} \\
{\left[\mathrm{N} / \mathrm{mm}^{2}\right]}\end{array}$ & $\begin{array}{c}f_{u \text { flange }} \\
{\left[\mathrm{N} / \mathrm{mm}^{2}\right]}\end{array}$ & $\begin{array}{c}f_{u, \text { average }} \\
{\left[\mathrm{N} / \mathrm{mm}^{2}\right]}\end{array}$ & $\begin{array}{c}\varepsilon_{u} \\
{[\%]}\end{array}$ \\
& 462 & 412 & 437 & 559 & 552 & 556 & 31 \\
\hline \multirow{2}{*}{ HEA160 } & $f_{y, \text { web }}$ & $f_{y, \text { flange }}$ & $f_{y, \text { average }}$ & $f_{u, \text { web }}$ & $f_{u, \text { flange }}$ & $f_{u, \text { average }}$ & $\varepsilon_{u}$ \\
& {$\left[\mathrm{~N} / \mathrm{mm}^{2}\right]$} & {$\left[\mathrm{N} / \mathrm{mm}^{2}\right]$} & {$\left[\mathrm{N} / \mathrm{mm}^{2}\right]$} & {$\left[\mathrm{N} / \mathrm{mm}^{2}\right]$} & {$\left[\mathrm{N} / \mathrm{mm}^{2}\right]$} & {$\left[\mathrm{N} / \mathrm{mm}^{2}\right]$} & {$[\%]$} \\
& 432 & 392 & 412 & 538 & 523 & 531 & 32 \\
\hline
\end{tabular}

Table 4. Mechanical Properties of the $8 \mathrm{~mm}$ Rebar Steel

\begin{tabular}{|c|ccc|}
\hline 8 mm rebars & $f_{y}\left[\mathrm{~N} / \mathrm{mm}^{2}\right]$ & $f_{u}\left[\mathrm{~N} / \mathrm{mm}^{2}\right]$ & $\varepsilon_{u}[\%]$ \\
& 523 & 646 & 14 \\
\hline
\end{tabular}

Table 5. Mechanical Properties of the $8 \mathrm{~mm}$ End-Plate Steel

\begin{tabular}{|c|ccc|cccc|}
\hline $\mathbf{8 m m}$ & $f_{y, \text { long. }}$ & $f_{y, \text { trans. }}$ & $f_{y, \text { average }}$ & $f_{u, \text { long. }}$ & $f_{u, \text { trans. }}$ & $f_{\text {u,average }}$ & $\varepsilon_{u}$ \\
end-plate & {$\left[\mathrm{N} / \mathrm{mm}^{2}\right]$} & {$\left[\mathrm{N} / \mathrm{mm}^{2}\right]$} & {$\left[\mathrm{N} / \mathrm{mm}^{2}\right]$} & {$\left[\mathrm{N} / \mathrm{mm}^{2}\right]$} & {$\left[\mathrm{N} / \mathrm{mm}^{2}\right]$} & {$\left[\mathrm{N} / \mathrm{mm}^{2}\right]$} & {$[\%]$} \\
& 669 & 565 & 600 & 709 & 663 & 678 & 17 \\
\hline
\end{tabular}

One important thing to be highlighted is the high elastic strength of the $8 \mathrm{~mm}$ end-plate; indeed, the average value of this elastic limit is equal to $600 \mathrm{Mpa}$ while the normal steel grade which was ordered for these plates was S355. This phenomenon induced very high overstrength effects which were not expected and which were therefore not considered in the joint design presented in $\S 2.2$.

\subsubsection{Concrete (C25/30 concrete)}

To characterise the compression resistance of the concrete, twelve tests on cube and two on cylinder were performed. For the cubes, tests were achieved at different times ( 3 cube tests at day 7 , 14, 28 and the day of the test (day 72)) to observe the evolution of the concrete resistance; also, the equivalent resistances which would have been obtained on cylinder, which represents the characteristic value $f_{c k}$ as defined in the Eurocodes, have been computed according to the Eurocode 2 rules (EN 1992-1-1 [7]).

The average value which has been obtained through these tests for $f_{c k}$ is equal to $36 \mathrm{~N} / \mathrm{mm}^{2}$.

\subsection{Geometrical Measurements}

The geometrical measurement aim is to obtain the actual geometrical properties of the constitutive elements of the substructure and to check if they correspond to the elements which were ordered. In fact, insignificant divergences were observed (Demonceau [2]).

\subsection{Description of the Loading Sequence followed during the Test}

As previously mentioned, all the forces have been applied "statically" (i.e. progressive removal of the column), what means that the dynamic effects resulting from the impact action and the column loss itself have not been taken into account. It is justified hereafter:

- The objective is to understand the "physical" phenomena linked to the loss of a column in a frame. So, that is why it was decided to remove progressively the column so as to be able to observe all these phenomena and to measure them. 
- Another reason is that the final aim of the test is to validate later on numerical tools and analytical developments. To reach this goal, it was needed to measure all the displacements, rotations, loads and strains during the column loss, what was only possible with a progressive removal of the column.

The loading sequence during the test was the following one:

- A uniformly distributed load is first applied to the internal beams; during this phase, two locked jacks are placed at the middle of the substructure to simulate the presence of the column, as illustrated in Figure 18. In practice, the uniformly distributed load is applied with steel plates and concrete blocks, as shown in Figure 19; it represents a total load of $6 \mathrm{kN} / \mathrm{m}$; also, L-shaped profiles are placed so as to maintain the steel plates and the concrete blocks at their place when large deflections will take place (see Figure 19). The $6 \mathrm{kN} / \mathrm{m}$ load is smaller than the one to be considered for the ULS verifications under the accidental combination of actions $(\cong 10 \mathrm{kN} / \mathrm{m})$; however, it is the maximum load that could be "safely" applied in the laboratory during the test.

- In a second step, the support brought by the jacks is progressively removed by unlocking the jack; when it is achieved, the "free deflection" of the system is observed. The next step consists in imposing a further vertical displacement to the beams through the use of two jacks located at the top of the column thus (see Figure 20). The displacement is increased until failure of the substructure.

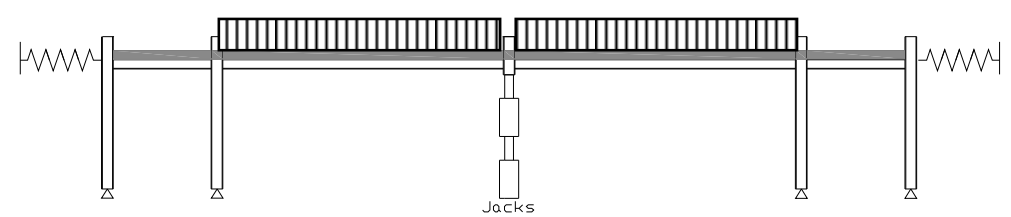

Figure 18. Column at the Middle Simulated by Two Locked Jacks

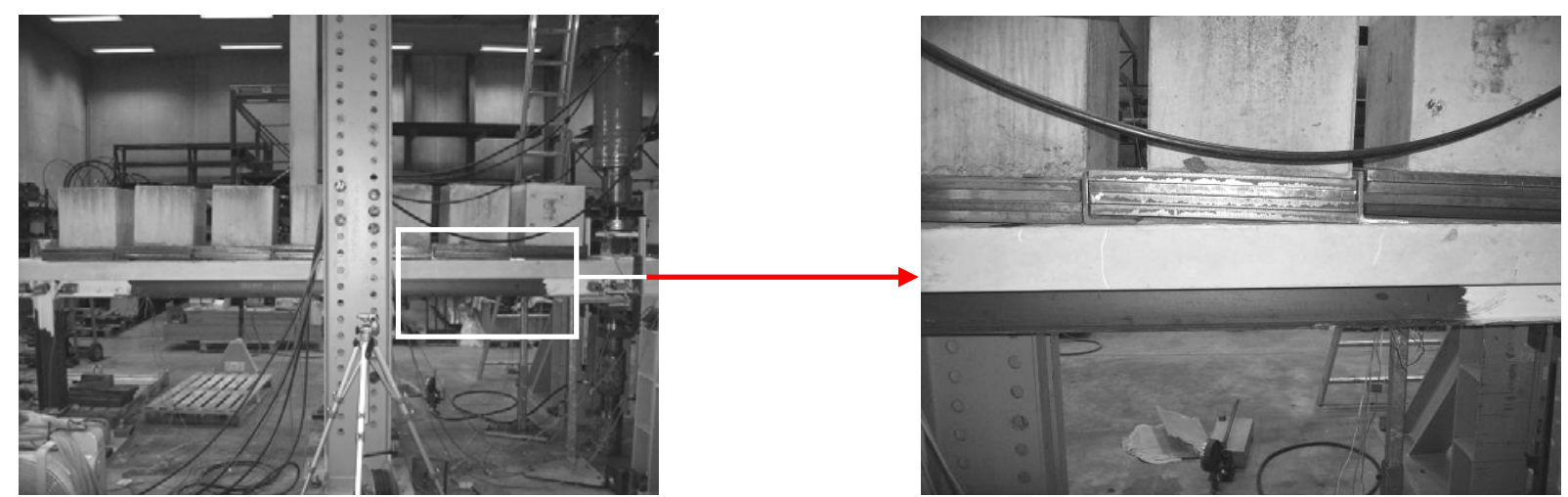

Figure 19. Steel Plates and Concrete Blocks Simulating the Uniformly Distributed Load

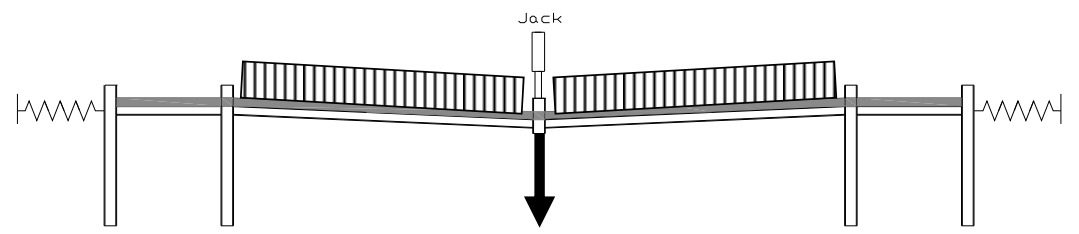

Figure 20. Application of a Further Vertical Displacement with Two Vertical Jacks

\section{$4.4 \quad$ Test Equipment}

\subsubsection{Hydraulic jacks (controlled displacement)}

In total, six hydraulic jacks are used during the test: 
- to simulate the presence of the column at the middle of the tested specimen, two screw jacks are initially placed under the beams (see Figure 18);

- then, to increase further the vertical displacement until collapse, two hydraulic jacks are placed in series at the top of the column so as to reach a maximum displacement capacity of $800 \mathrm{~mm}$;

- as previously mentioned, the lateral restraints are simulated at each side of the substructure by "hollow" jacks (see Figure 21) with a displacement capacity of $200 \mathrm{~mm}$.

The applied loads at all these jacks are measured through load cells.

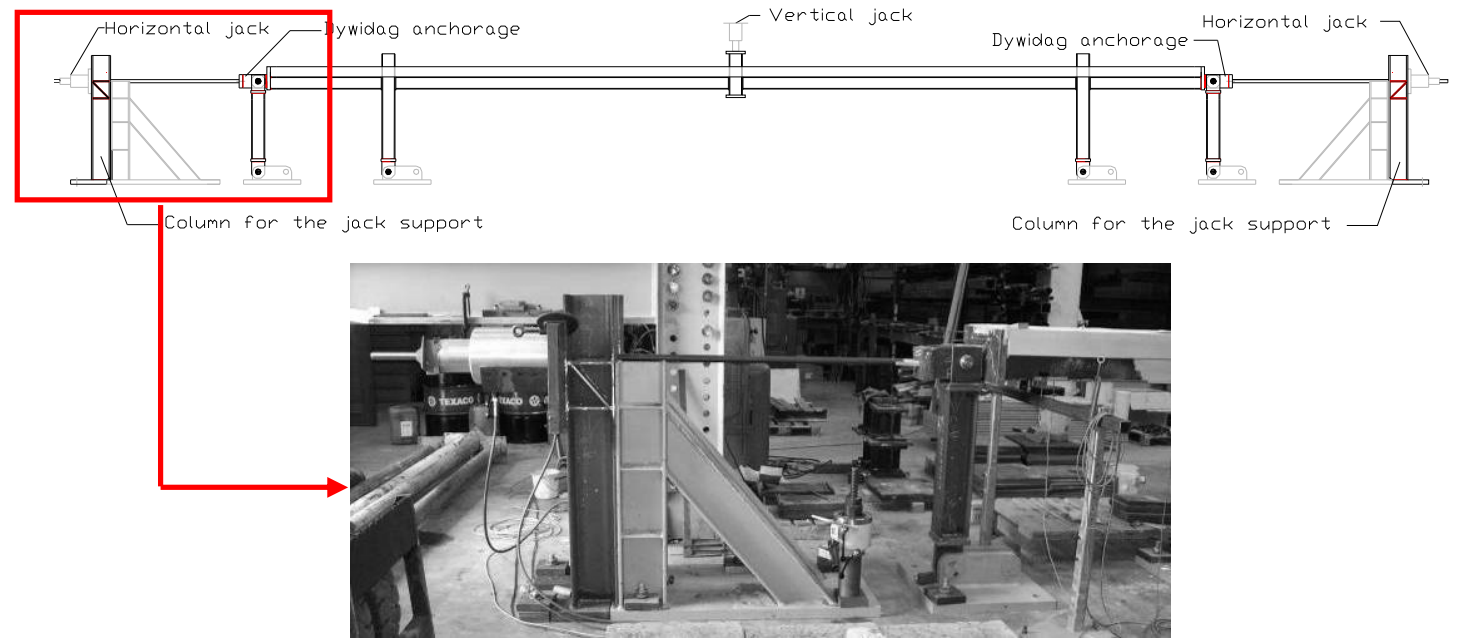

Figure 21. Horizontal Restraint Simulated by Horizontal “Hollow” Jacks

\subsubsection{Displacement and Rotational Transducers}

Five rotational transducers are placed in the vicinity of the joints as shown in figure 22 and four displacement transducers are placed as follows (see Figure 23):

- $\quad$ two at the middle of the substructure to measure the vertical displacement;

- $\quad$ one each side of the substructure to measure the horizontal displacement.

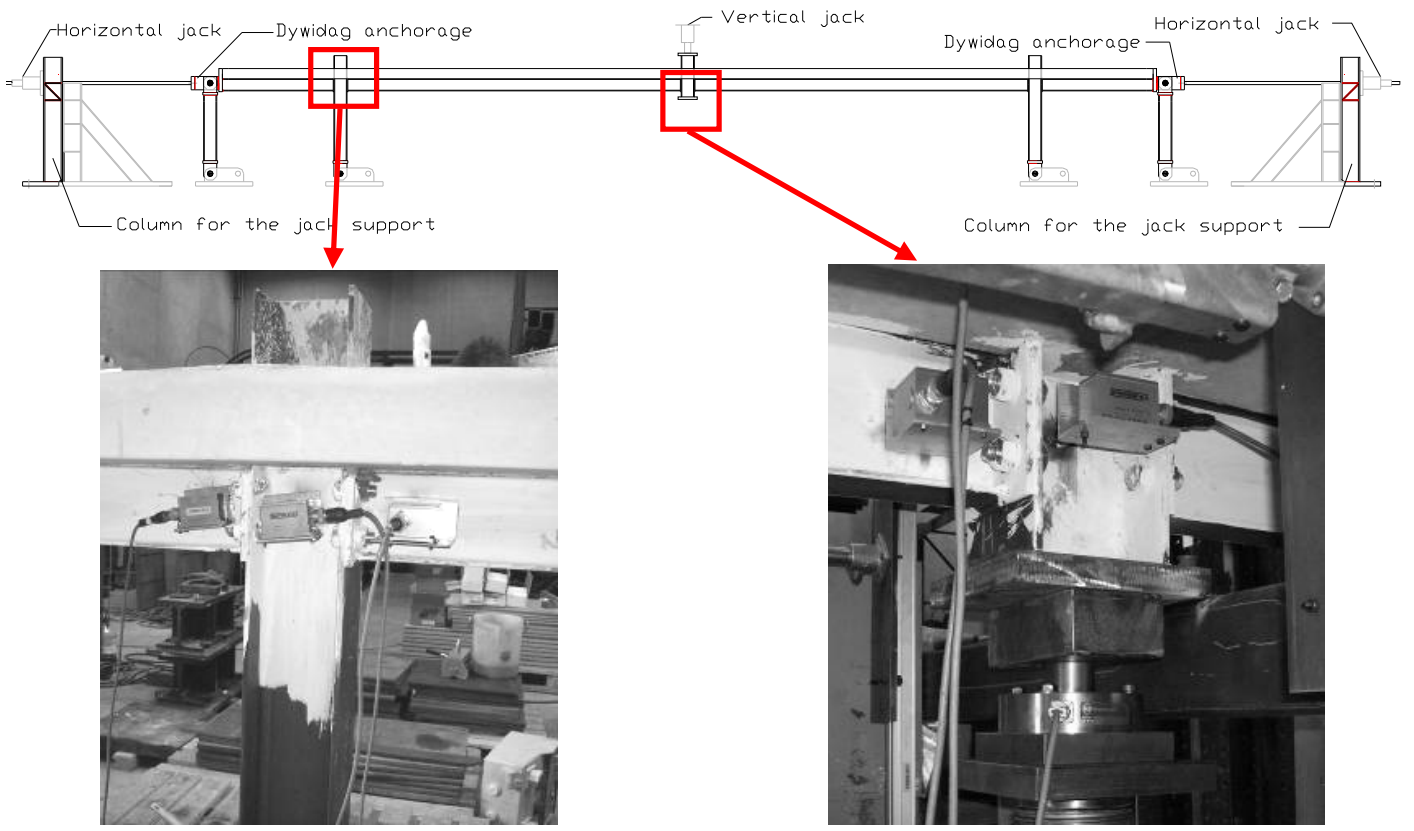

Figure 22. Rotational Transducers 


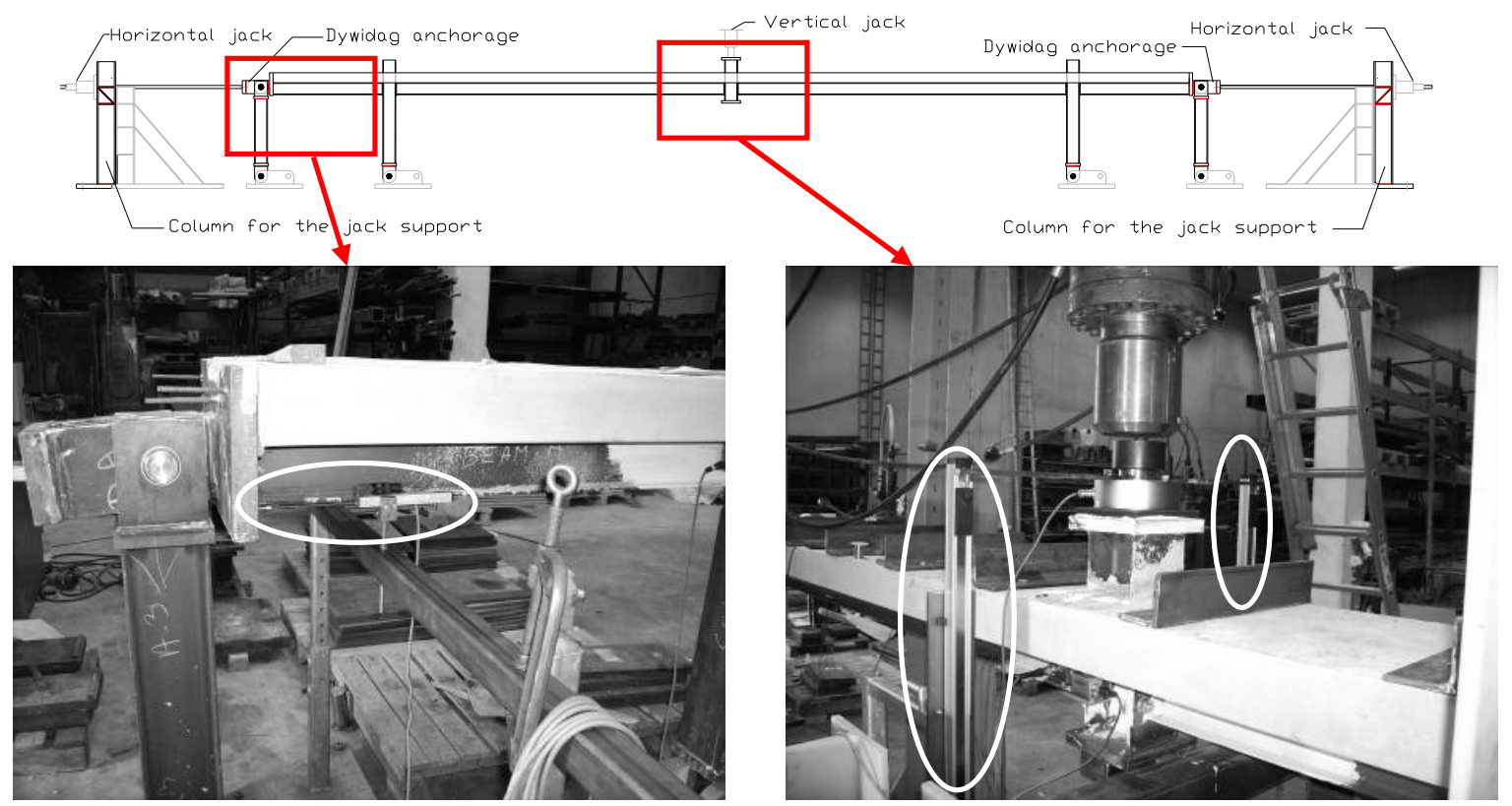

Figure 23. Displacement Transducers

\subsection{Substructure Test Results}

As explained in $\S 4.3$, a uniformly distributed load is first applied on the substructure with steel plates and concrete blocks. After the application of the latter, first small cracks are already observed in the concrete slab in the vicinity of the external composite joints.

The jacks at the middle are then unlocked and progressively removed. The system is completely released; a deflection of $29 \mathrm{~mm}$ is registered at that moment. At this stage, the width of the cracks at the vicinity of the external joints is bigger and first steel yielding is observed in the column web panel of the internal composite joints.

This first step of the test is illustrated by the part "OA" of the curve presented in Figure 24 and which represents the evolution of the vertical load acting on the beams at the middle of the substructure according to the vertical displacement under the "impacted" column. The vertical reaction in the lower column stub, before its removal, is equal to $33,5 \mathrm{kN}$ (value of the load at point "O"). From Figure 24, it can be seen that the structure remains globally elastic when " $A$ " is reached.

Then, as previously explained, a vertical displacement is progressively imposed until failure. During this stage, two “unloading-reloading” sequences are followed as illustrated in Figure 24.

From point "A" to "B" in Figure 24, the substructure yields progressively to finally form a beam plastic mechanism at point " $B$ " with formation of the plastic hinges in the joints. At that moment, the cracks in the vicinity of the external composite joints are more pronounced and yielding of some steel components of the joints is clearly observed (column web and beam flange in compression - see Figure 25 and Figure 26). Also, for the internal composite joint, a detachment of the end-plate and of the column flange is observed (see Figure 26).

From point "B" to "C" in Figure 24, a plateau develops, what means that the vertical displacements increase with a constant vertical load (equal to $30 \mathrm{kN}$ ). All along the plateau, the concrete cracks in the vicinity of the external composite joints continue to extend and yielding spreads further in the 
steel joint components. One important observation is that the concrete in the vicinity of the internal composite joint crushes in compression (Figure 27).

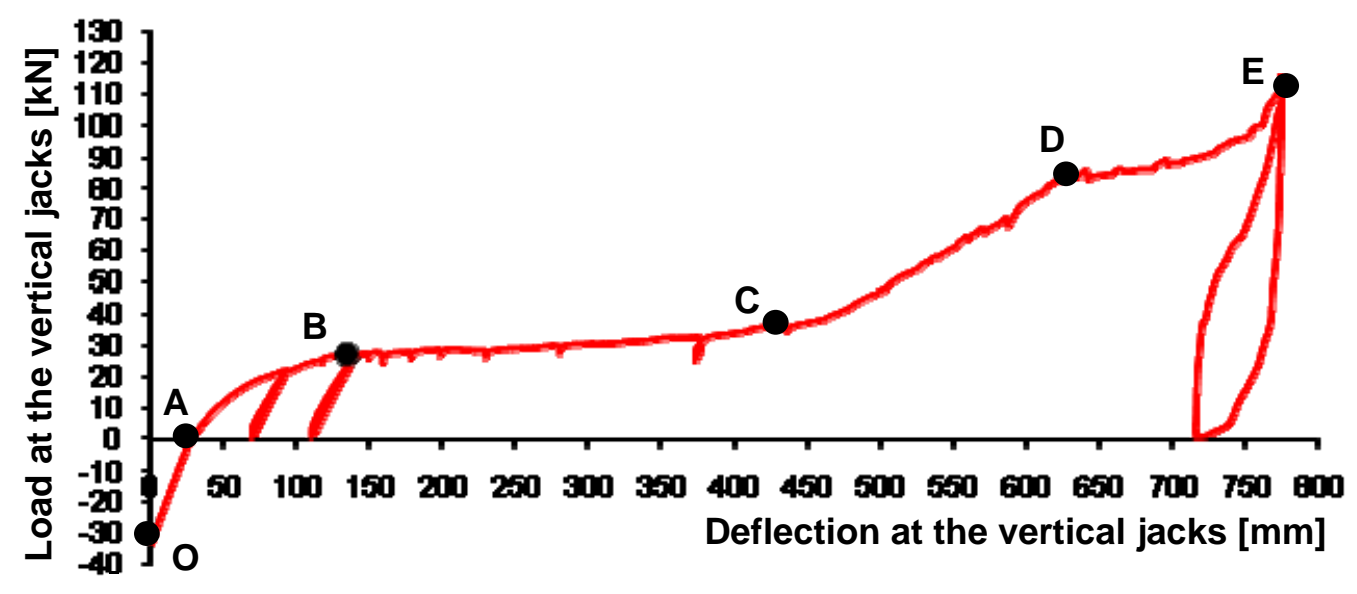

Figure 24. Vertical load vs. Vertical Displacement Curve
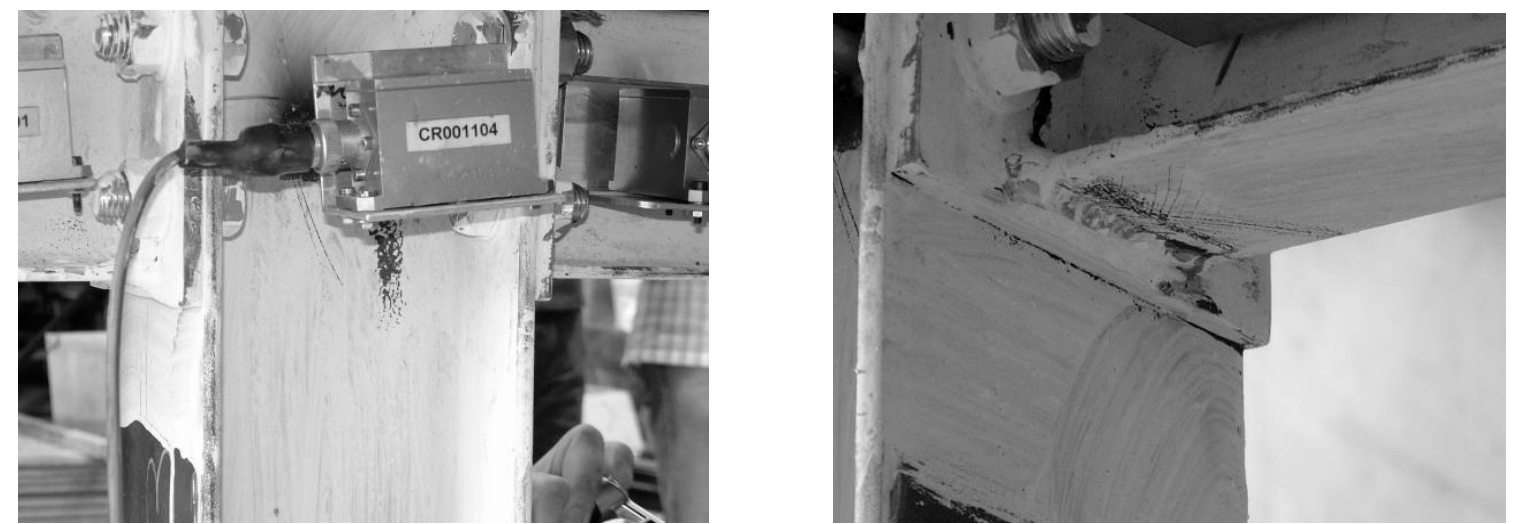

Figure 25. Yielding of Steel Components at the External Composite Joints

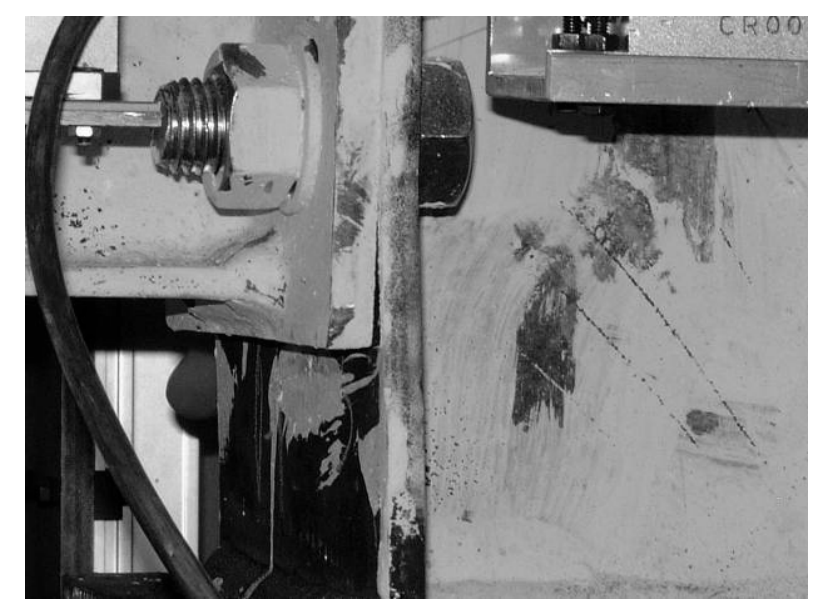

Figure 26. Yielding of Steel Components at the Internal Composite Joints 

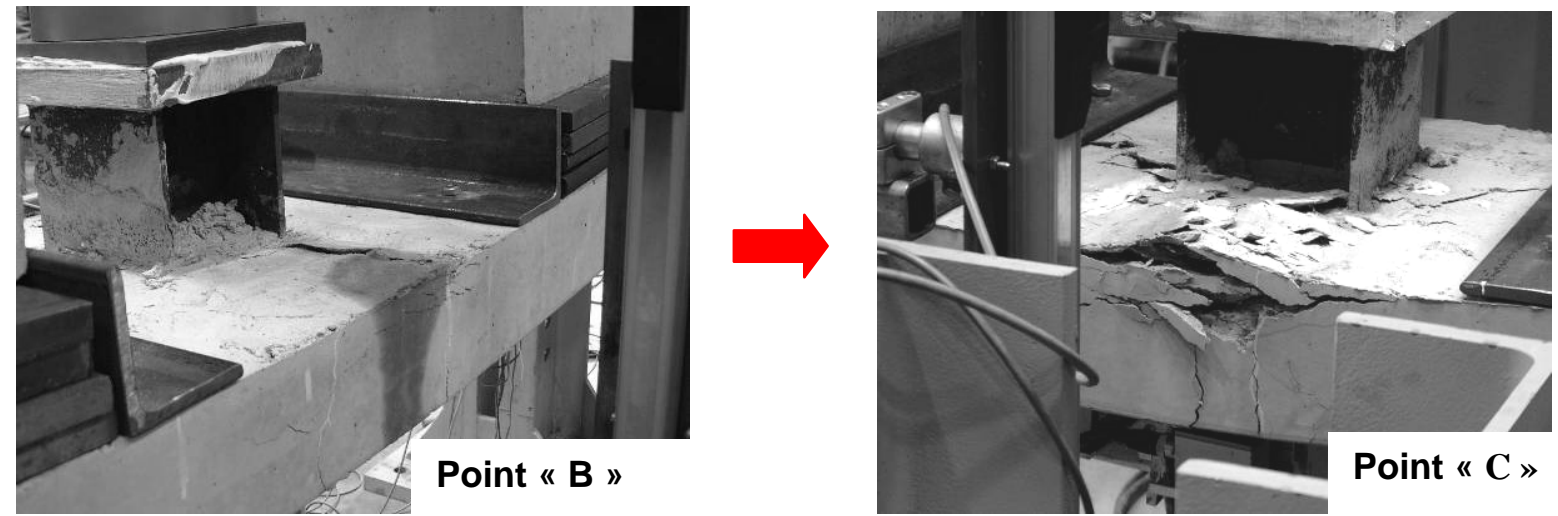

Figure 27. Concrete Splitting at the Internal Composite Joint

The horizontal jacks begin to be significantly activated at point " $C$ " in Figure 24; at this point, membrane forces start to develop as confirmed by the shape of the global displacement curve (part "CD" in Figure 24). At point " $D$ ", the longitudinal rebars in the external composite joints suddenly fail (see Figure 28) and the external joints work later on as steel ones. Yielding affects the different components in the internal and external composite joints as illustrated in Figure 29 and Figure 30. At point " $D$ ", a loss of stiffness related to the failure of the rebars is observed in Figure 24; indeed, when these rebars fail, both flexural and tensile stiffness of the external joints decrease, what directly induces the development of further membrane effects.

However, it can be observed that the failure of the rebars does not lead to the failure of the substructure; indeed, after point " $\mathrm{D}$ ", the vertical load at the vertical jacks still increases with the imposed displacement (part "DE" of the curve in Figure 24).

This is possible as long as the steel connection is able to support, alone, the membrane forces developed in the system. In addition, associated to the loss of the rebars, the vertical displacements are increasing with a low variation of the vertical loads. These additional vertical displacements induce an increase of the membrane forces as confirmed by Figure 31 showing the evolution of the load in the horizontal jacks at the specimen extremities versus the vertical load in the vertical jacks. So, the steel connection working alone has at the end to be sufficiently resistant to support these additional membrane forces and sufficiently ductile to support the additional rotations associated to the vertical displacement. The capacity of the steel connections, working alone, to support significant membrane forces has been confirmed by tests on joint in isolation performed at Stuttgart University (Kuhlmann [1]).
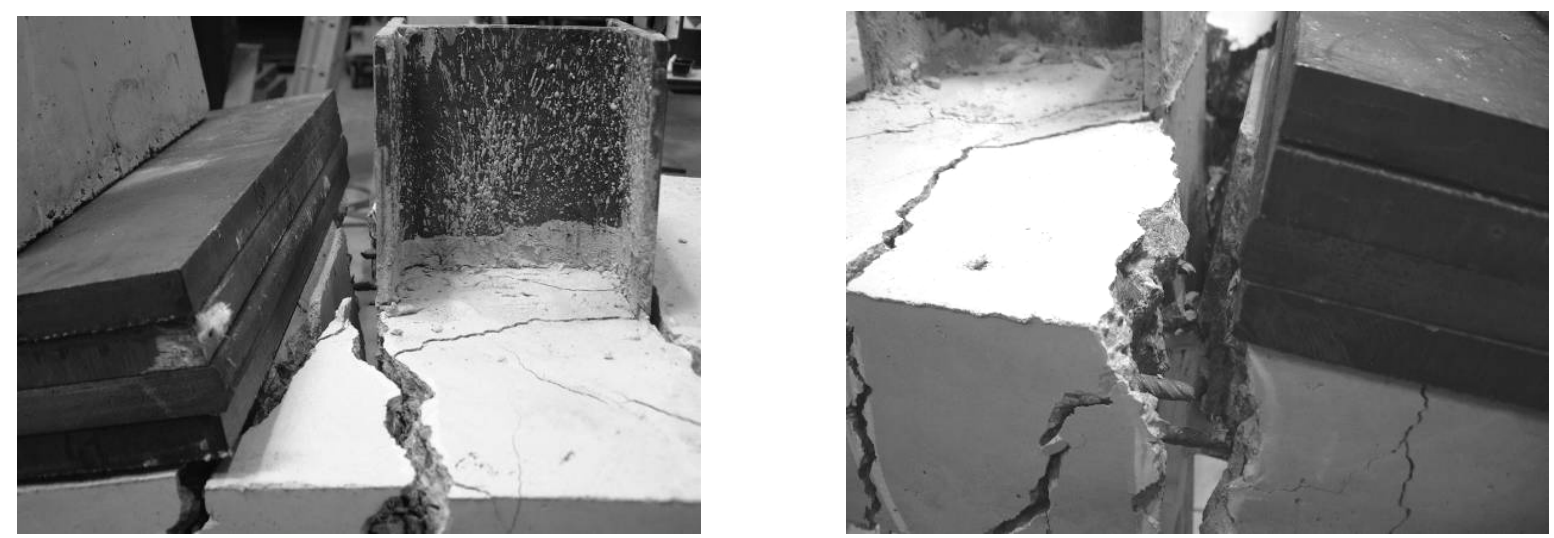

Figure 28. Collapse of the Longitudinal Rebars in the Vicinity of the External Composite Joints 

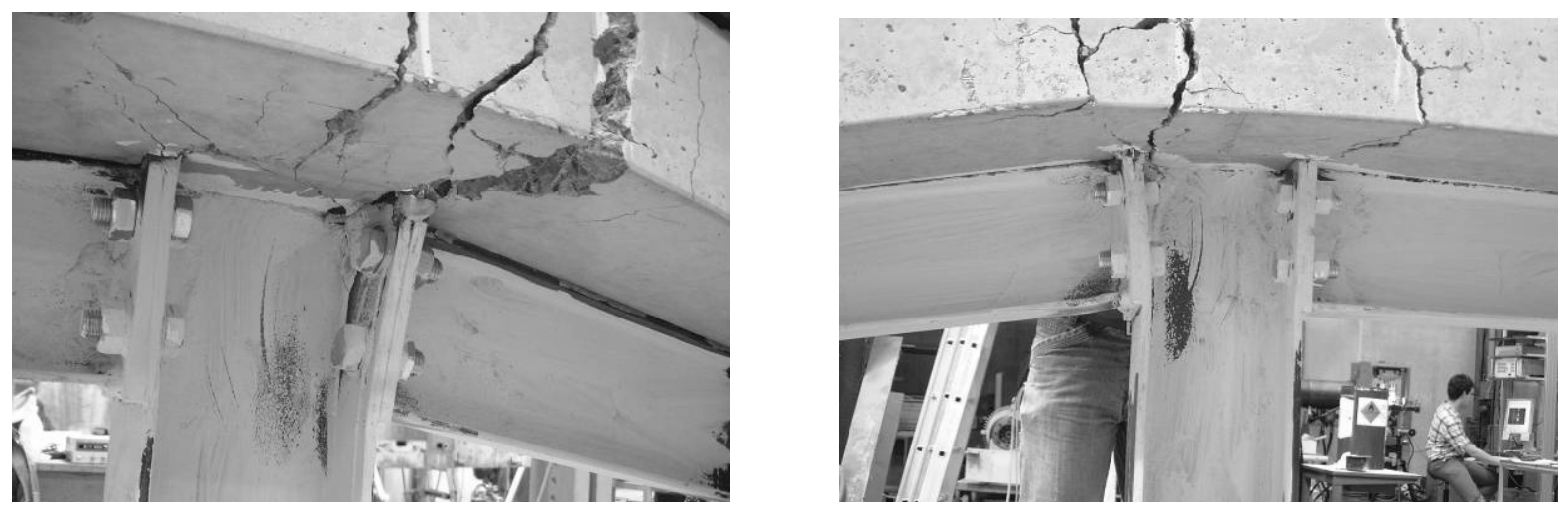

Figure 29. Spread of Yielding in the Steel Components of the External Composite Joints

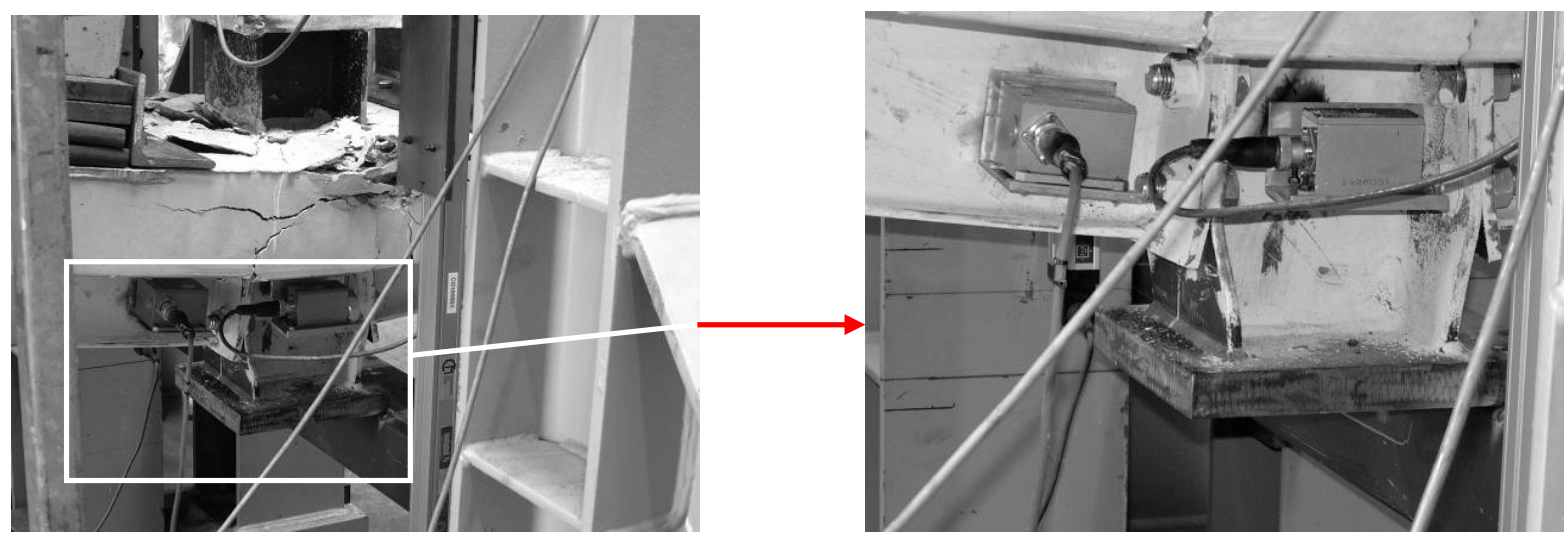

Figure 30. Deformation of the Internal Composite Joint at Point “D” of Figure 24

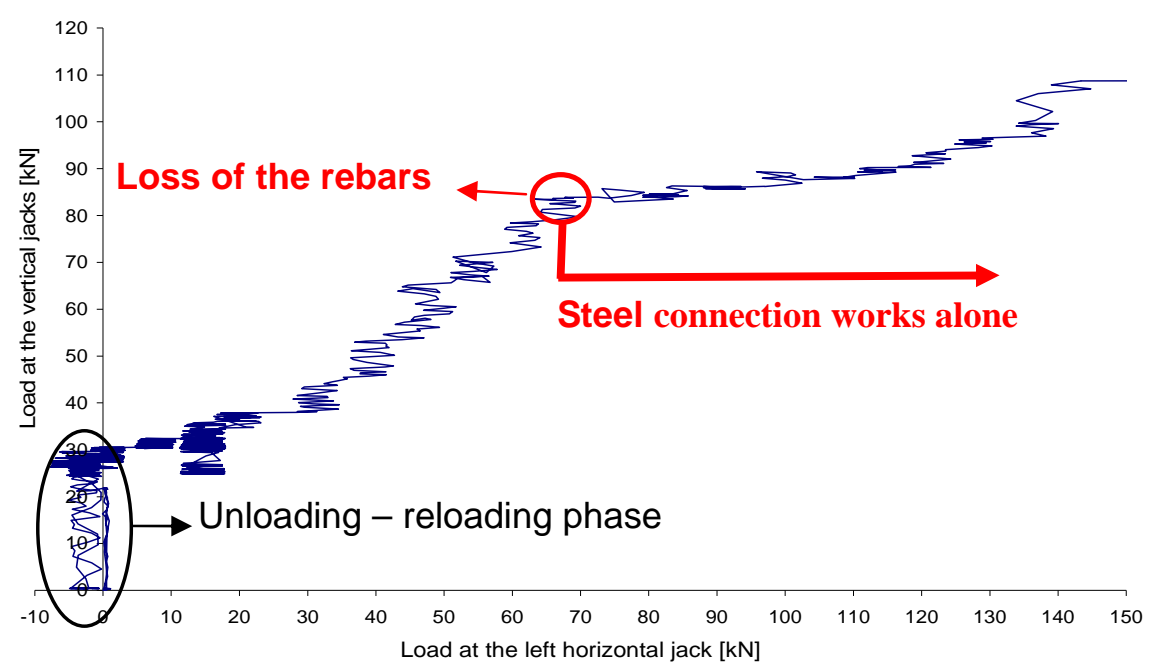

Figure 31. Evolution of the Load in the Left Horizontal Jack according to the Applied Vertical Load at the Middle of the Specimen

The test was stopped with the occurrence of cracks in the weld between the bottom flange of the IPE140 beam and the end-plate in one of the internal composite joints.

At the end of the test, a maximum vertical displacement of $775 \mathrm{~mm}$ is reached for a vertical load at the vertical jacks of $114 \mathrm{kN}$; the deformation of the specimen at this stage may be seen in Figure 32 . The maximum horizontal displacement at each side of the structure is equal to $45 \mathrm{~mm}$ for a horizontal load of $147 \mathrm{kN}$; the observed horizontal displacement appears clearly in Figure 33.

Also, at point E of Figure 24, all the joint components of the internal and external composite joints suffer large deformations and yielding as seen in Figure 34 and Figure 35 (after the damage 
concrete has been removed). In particular:

- for the external composite joints: yielding of the column web in compression, the beam flange and web in compression, the column flange in bending.

- for the internal composite joints: yielding of the column web in tension (Luders bands) associated to the membrane forces, column flange in bending, beam flange and web in tension.

The evolution of the joint rotations versus the load acting in the vertical jacks is given in Figure 36. The maximum joint rotations reached at the end of the test are equal to $11^{\circ}(192 \mathrm{mrad})$ and to $9,5^{\circ}$ (166 mrad), for the internal and external composite joints respectively. It can be observed in Figure 36 that:

- the behaviour of the internal and external composite joints is quite similar;

- the joint rotations are mainly associated to the yielding of the connection elements;

- a beam plastic mechanism develops with formation of plastic hinges in the joints.

From the maximum rotation values observed at the end of the test, it can be concluded that the joints exhibited a very ductile behaviour with a very high rotation capacity, as expected. Also, through these observations, it is confirmed that, even if the collapse mode under hogging bending moment is associated to the component "beam flange in compression", the ductility of the joint is sufficient to develop the catenary action, as predicted in $\S 2.2$.
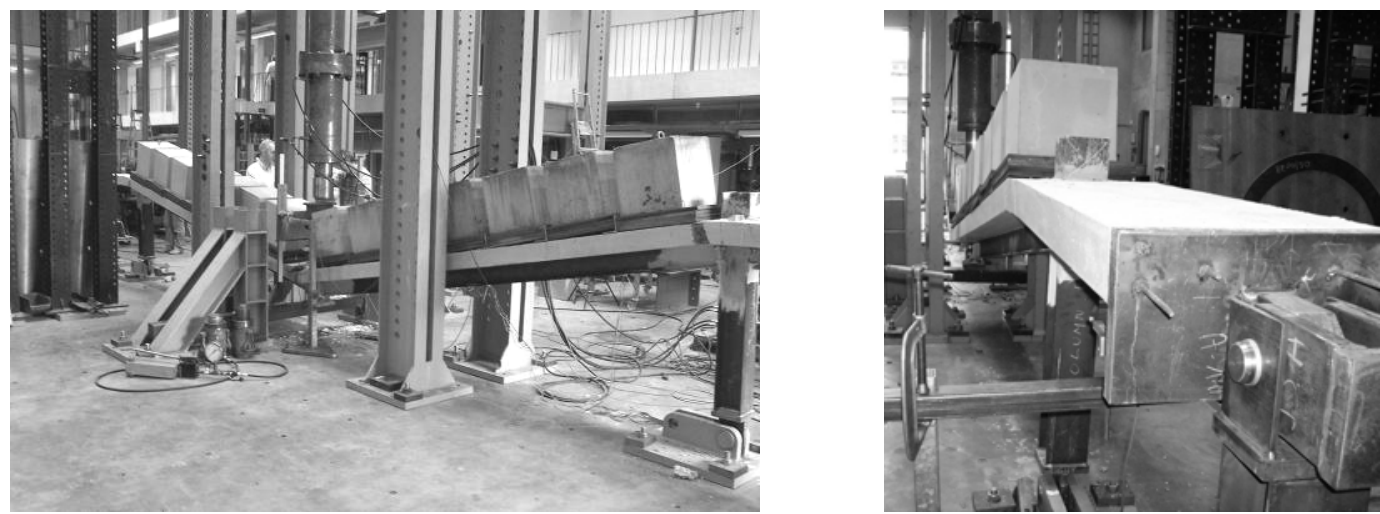

Figure 32. Deformation of the Specimen at Point "E" of Figure 24

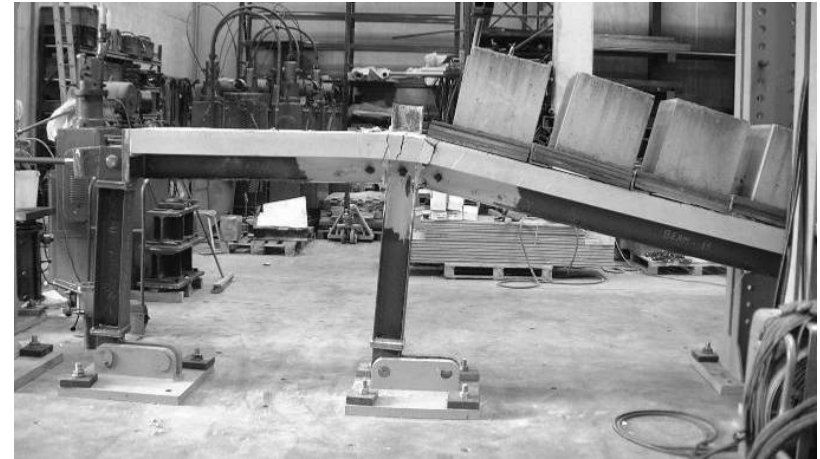

Figure 33. Horizontal Displacement of the Specimen at Point "E” of Figure 24 

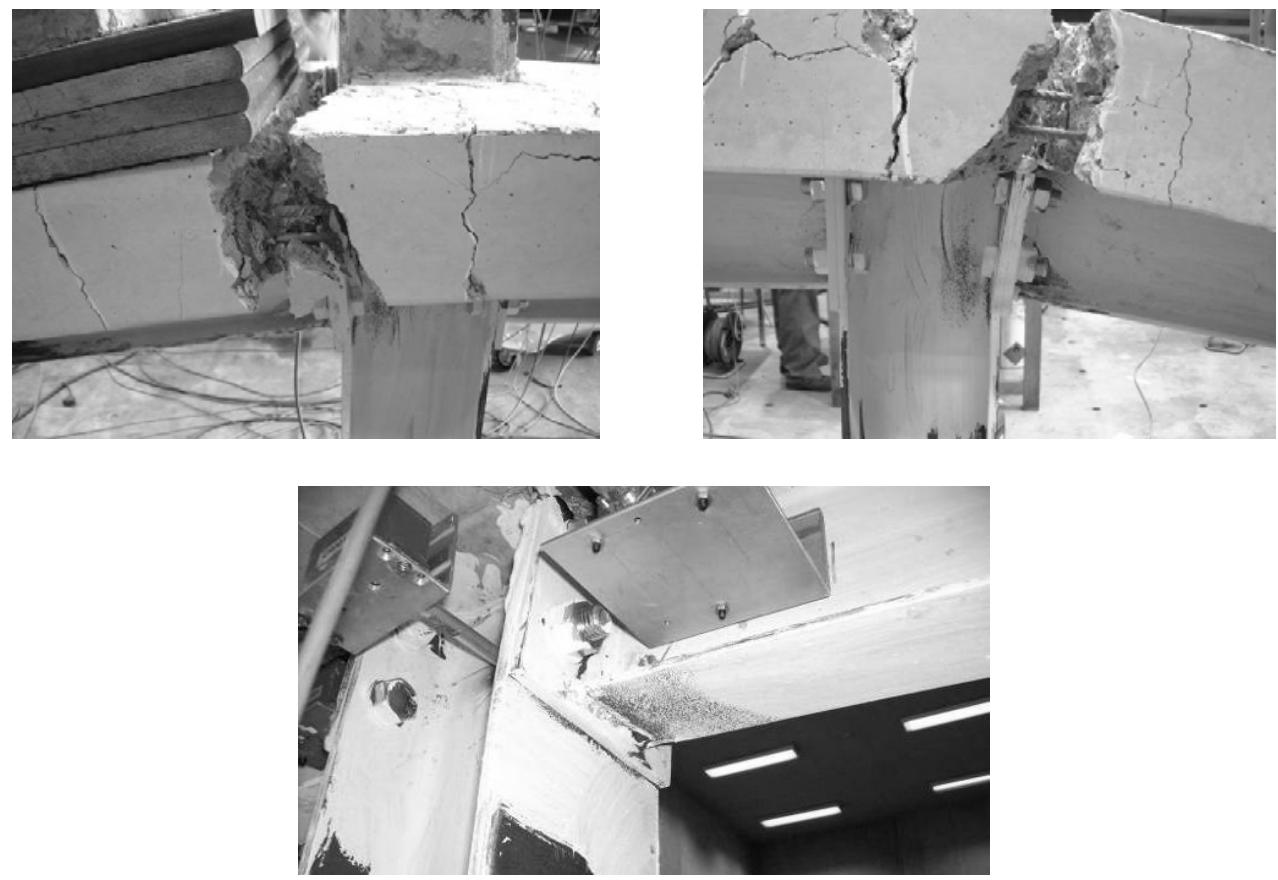

Figure 34. External Composite Joints at the End of the Test
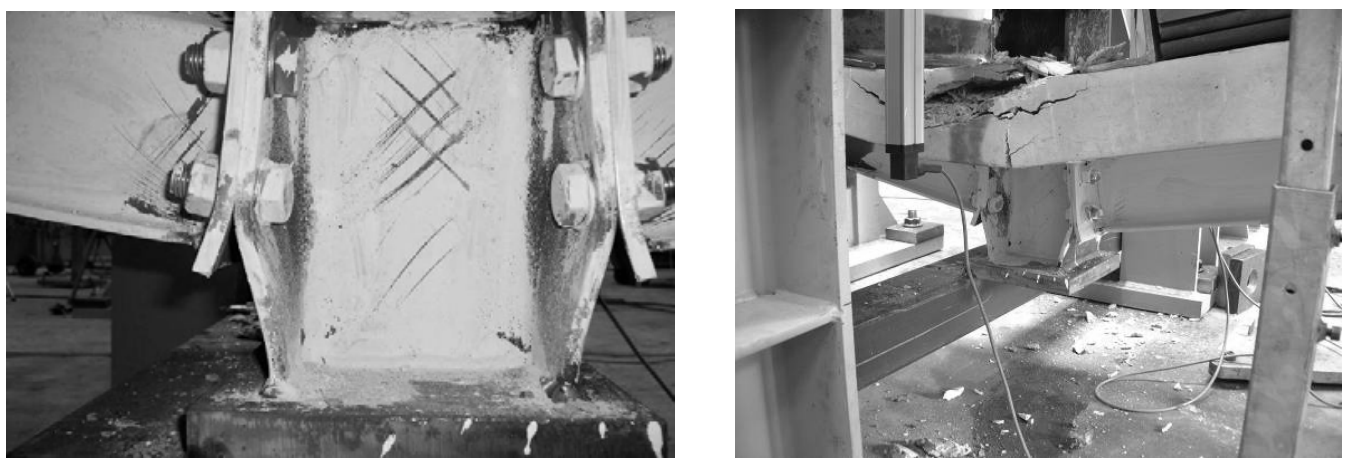

Figure 35. Internal Composite Joints at the End of the Test

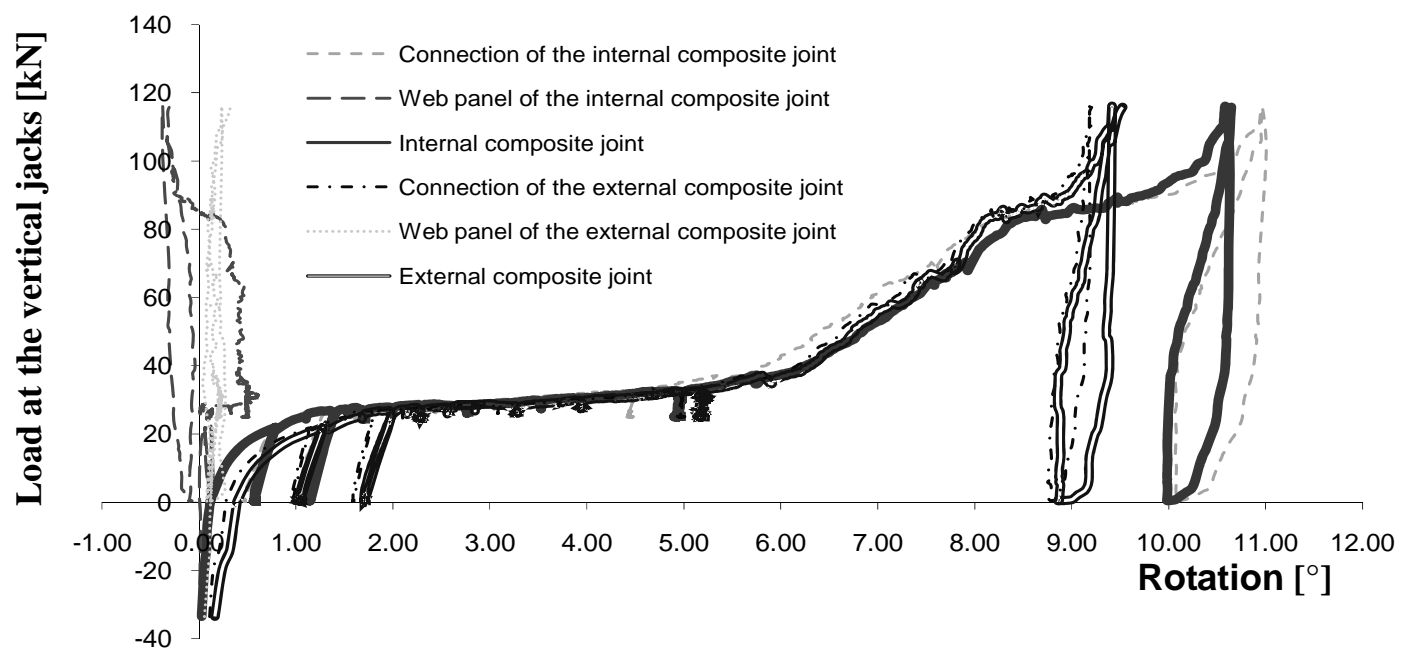

Figure 36. Rotation of the Internal and External Composite Joints 
After the test, the steel plates and the concrete blocks were removed so as to see the location of the cracks along the concrete slab. As shown in Figure 37, two big cracks appeared during the test in the vicinity of the external composite joints. This observation can be explain by the fact that, in the tested substructure, the composite joint configuration are composed of flush end-plates with the upper part embedded in the concrete slab; so, when the end-plates deform, the embedded part deformation can easily initiate a crack in the reinforced concrete slab as illustrated in Figure 38. However, the joints exhibited a very ductile behaviour during the test although to have one big crack is not the best situation from the ductility point of view.
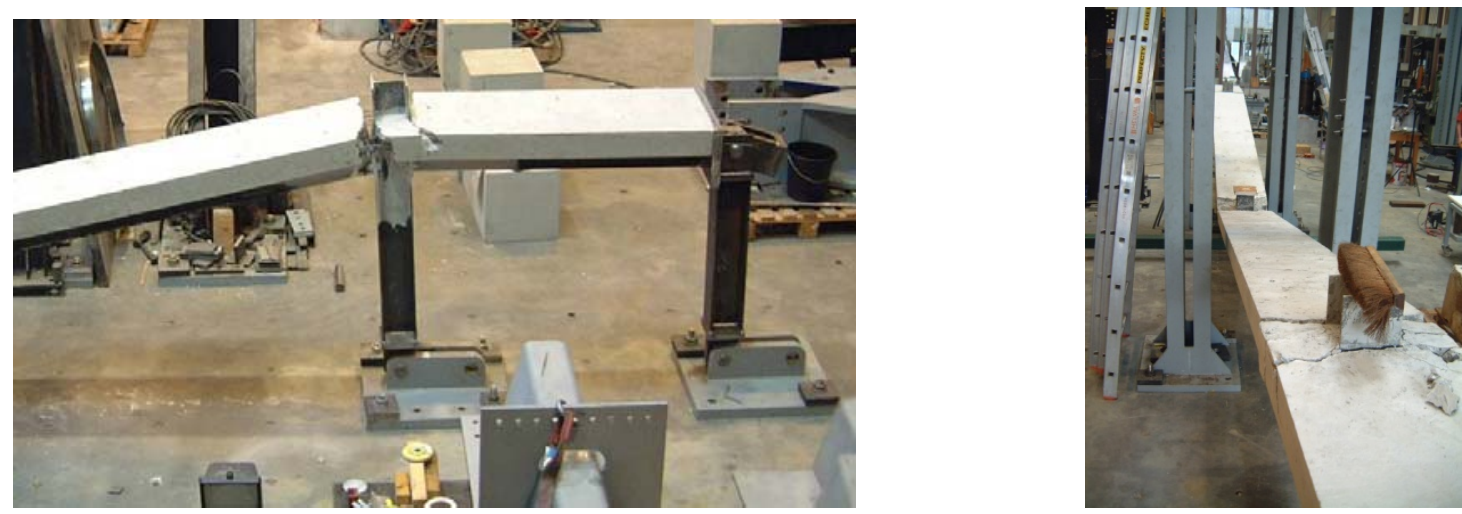

Figure 37. Distribution of the Cracks in the Concrete Slab

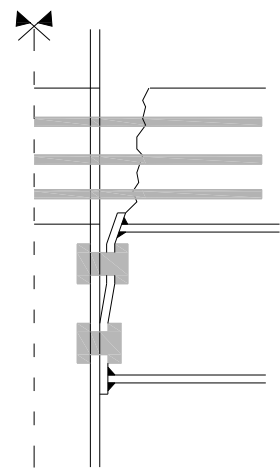

Figure 38. Crack associated to the Deformation of the End-Plate Embedded in the Concrete Slab

\section{CONCLUSIONS}

As part of a global research and development strategy, a laboratory test aiming at the simulation of the loss of a column in a composite frame has been carried at Liège University. The objective was to observe the development of membrane forces in the beams further to the loss of the column as well as the effects of these forces on the joint response.

The tested specimen was extracted from an actual frame designed according to Eurocode 4 recommendations and that, for conventional loading, i.e. design loads recommended in Eurocode 1, without specific account of exceptional events as the "loss of a column". The specimen and the test configuration were defined so as to get a behavioural response as close as possible to the one that the actual frame would have exhibited.

The main measurements which were registered are the vertical displacement at the level of the lost column, the rotations within the structural joints and the horizontal displacements and forces appearing at the specimen extremities. 
The test, which constitutes a European "premiere", was successful and all the phenomena under investigations were registered. Indeed, the development of membrane forces in the system was observed, what was confirmed by the measurement of membrane forces in the beams. Also, the composite joints loaded by combined tensile forces and bending moments exhibited a ductile behaviour as expected.

The results obtained through this test have been used to investigate the validity of a numerical FEM tool and to develop analytical models in (Demonceau [2]) which is freely downloadable at http://orbi.ulg.ac.be/handle/2268/2740.

\section{References}

[1] Kuhlmann U., Rolle L., Jaspart J.-P., Demonceau J.-F., Vassart O., Weynand K., Ziller C., Busse E., Lendering M., Zandonini R. and Baldassino N., "Robust structures by joint ductility”, Final report of the RFCS project N RFS-CR-04046, 2008 (report accepted - to be published).

[2] Demonceau J.-F., "Steel and composite building frames: sway response under conventional loading and development of membrane effects in beams further to an exceptional action", $\mathrm{PhD}$ thesis presented at Liège University, 2008 (downloadable at http://orbi.ulg.ac.be/handle/2268/2740).

[3] EN 1994-1-1, "Eurocode 4: Design of steel and concrete structures- Part 1-1: general rules and rules for buildings”, CEN - European Committee for Standardization, December 2004.

[4] EN 1991-1-1, "Eurocode 1: Actions on structures - Part 1-1: General actions - Densities, self-weight, imposed loads for buildings”, CEN - European Committee for Standardization, April 2002.

[5] EN 1998-1. "Eurocode 8: Design of structures for earthquake resistance - Part 1: General rules, seismic actions and rules for buildings”. European CEN - European Committee for Standardization, December 2004.

[6] Kuhlmann U. and Schäfer M., "Innovative verschieblichte Verbund-Rahmen mit teiltragfähigen Verbund-Knoten“, Forschung für die Praxis P 505, Forschungsvereinigung Stahlanwendung e.V. im Stahl-Zentrum, 2004.

[7] EN 1992-1-1, "Eurocode 2: Design of concrete structures - Part 1-1: General rules and rules for buildings”, European CEN - European Committee for Standardization, December 2004. 